\author{
Ernest $\mathrm{O}$. Lawrence \\ Radiation Laboratory
}

\title{
CONCENTRATION AND VELOCITY PROFILES IN A STEFAN DIFFUSION TUBE
}

Berkeley, California 


\section{DISCLAIMER}

This report was prepared as an account of work sponsored by an agency of the United States Government. Neither the United States Government nor any agency Thereof, nor any of their employees, makes any warranty, express or implied, or assumes any legal liability or responsibility for the accuracy, completeness, or usefulness of any information, apparatus, product, or process disclosed, or represents that its use would not infringe privately owned rights. Reference herein to any specific commercial product, process, or service by trade name, trademark, manufacturer, or otherwise does not necessarily constitute or imply its endorsement, recommendation, or favoring by the United States Government or any agency thereof. The views and opinions of authors expressed herein do not necessarily state or reflect those of the United States Government or any agency thereof. 


\section{DISCLAIMER}

Portions of this document may be illegible in electronic image products. Images are produced from the best available original document. 
U.CRL- 10.421

UC 37 Instruments

TID 4500 (18 th Ed.)

\section{UNIVERSIT Y. OF CALIFORNIA}

Lawrence Radiation Laboratory

Berkeley, California

Contract No; W-7405-eng-48

\section{CONCENTRATION AND VELOCITY PROFILES}

IN A STEFAN DIFFUSION TUBE

Fred J. Heinzelmann, Darshanlàl T: Wasan, and Charles R。 Wilke

August .16, 1962 
Printed in USA. Price \$1.50. Available from the office of Technical Services

U. S. Department of Commerce Washington 25 , D.C. 
CONCENTRATION AND VELOCIT Y PROFILES

IN A STEFAN DIFFUSION TUBE

\section{Contents}

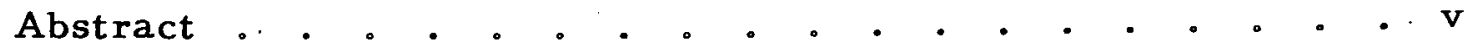

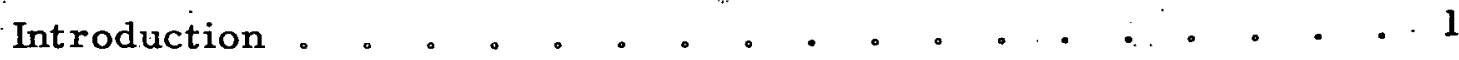

Theory

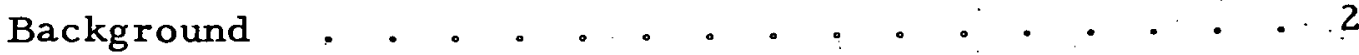

Theoretical Analysis . . . . . . . . . . . . . 3

Solution of the Concentration Distribution . . . . . . 11

Alternative Development for Obtaining the

Concentration and Velocity Profiles. .. . . . . . 18

Boundary Conditions. . . . . . . . . . . . . 20

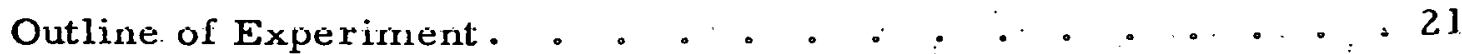

Apparatus 。 . . . . . . . . . . . . . . . 22

Diffusion System . . . . . . . . . . . . . . 22

Probe . . . . . . . . . . . . . . . . . 29

Equipment for Measuring Probe Resistance. . . . . . . 33

Probe-Calibration Cells . . . . . . . . . . . 33

Experimental Procedure . . . . . . . . . . . . . . 35

Results and Discussion

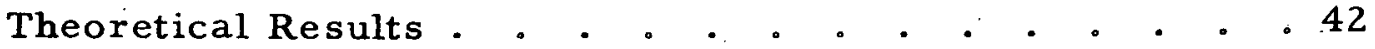

Experimental Verification. . . . . . . . . . . 45

Conclusions . . . . . . . . . . . . . . . . 51

Acknowledgments 。 . . . . . . . . . . . . . 52

Nomenclature 。 . . . . . . . . . . . . . 53

Appendices

A. Sample Calculation of $\mathrm{C}_{1}$ at $\mathrm{x}=0 . . . . . . .54$

B. Probe Calibration Curves . . . . . . . .60

C. Diffusion Data Summary . . . . . . . . . . 64

References . . . . . . . . . . . . . . . . 66 


\section{THIS PAGE}

\section{WAS INTENTIONALLY}

LEFT BLANK 


\title{
CONCENTRATION AND VELOCITY PROFILES
} IN A STEEAN DIFFUSION TUBE

\author{
Fred J. Heinzelimann, Darshanlal T. Wasan, and Charles R. Wilke \\ Lawrence Radiation Laboratory and Department of Chemical Engineering \\ University of California, Berkeley, California
}

\section{August 16, 1962}

\begin{abstract}
The Stefan diffusion tube has been widely used as a means of determining vapor-phase diffusion coefficients. By this method the diffusion coefficient has been calculated on the assumption of plugflow (flat) concentration and velocity profiles in the diffusion tube. These assumptions have been examined theoretically and experimentally in this study.

The theoretical study and the experimental results indicate that the concentration profile is flat across the diffusion tube. The velocity profile was found to be developing from a flat one near the liquid surface to a parabolic one at the other end of the tube. However, it has been shown theoretically that the shape of the velocity profile does not affect the mass flux provided the concentration profile is.flat. Thus diffusion data that have been calculated from Stefan diffusion tube data with the plug flow approximation are correct.
\end{abstract}




\section{INTRODUCTION}

The Stefan diffusion tube has been widely used for the determination of vapor-phase diffusion coefficients. The diffusion coefficients have been calculated from the measured mass flux, assuming flat concentration and velocity profiles. These assumptions have not previously been verified, although intuitively one would expect them to be essentially correct.

This report describes a theoretical analysis of the flow system and an experiment designed to determine whether or not the flat-profile assumptions are valid. The equations of motion were coupled. with the diffusion equation to obtain theoretical velocity and concentration profiles. The results were then verified by an experimental measurement of the concentration profile, using a modification of a thermal conductivity cell. The system used for the experiment was benzene diffusing through stagnant air at $35^{\circ} \mathrm{C}$ and $748 \mathrm{~mm} \mathrm{Hg}$. 


\section{THEORY}

\section{Background}

The equations for isothermal diffusion are well known, having first been developed by, Maxwell ${ }^{1}$ and Stefan. ${ }^{2,3}$. For the ith component, these equations have the form

$$
-\frac{P}{R T} \frac{d y_{i}}{d x}=\sum_{j \neq i}^{n} \frac{N_{i} y_{j}-N_{j} y_{i}}{D_{i j}}
$$

This equation, in the case of binary diffusion, which is the case of interest in this study, can be transformed into 4

$$
N_{A}=\frac{-D_{A B} P}{R T} \frac{d y_{A}}{d x}+\left(N_{A}+N_{B}\right) y_{A}
$$

This equation is defined by Bird, et al. ${ }^{5}$ as Fick's first law in terms of $\mathrm{N}_{\mathrm{A}}$, relative to stationary coordinates.

. With component B stagnant, $i_{\circ} e_{\circ}, N_{B}=0$, the equation becomes

$$
N_{A}=\frac{-D_{A B}{ }^{P}}{R T} \frac{d y_{A}}{d x}+N_{A} y_{A} \text {. }
$$

The first term on the right-hand side is the contribution of equimolal diffusion; the second term is interpreted as the contribution to the flux of $A$ due to the bulk.flow set up by the diffusion. Integration of Eq. (3), assuming $D_{A B}$ constant, gives 4

$$
\mathrm{N}_{\mathrm{A}}=\frac{\mathrm{D}_{\mathrm{AB}} \mathrm{P} \Delta \mathrm{p}}{\mathrm{RT \Delta x}\left(\mathrm{p}_{\mathrm{f}}\right)},
$$

where $\left(p_{f}\right)$ is the diffusion-film-pressure factor. It is defined as

$$
p_{f}=\frac{\left(P-p_{S}\right)-\left(P-p_{0}\right)}{\ln \frac{P-p_{S}}{P-p_{0}}}
$$

Equation (4) is used to calculate diffusion coefficients from mass flux data obtained in the Stefan tube apparatus. 
Inherent in the integration of Eq. (3) is the assumption that the velocity and concentration profiles in the Stefan tube are flat; $i$ 。 the model.is a plug flow one. This study was undertaken to check the above assumptions theoretically and experimentally.

Theoretical Analysis

Consider the diffusion system shown in Fig. 1. Liquid A is evaporating into a stagnant column of gas $B$. Right at the liquid-gas interface $(x=0)$ the gas phase concentration of $A_{9}$ corresponding to equilibrium with the liquid, is denoted by $\mathrm{C}_{\mathbf{S}^{\circ}}$

At the top of the tube $(x=L)$ a stream of gas $B$ flows past slowly. The whole system is kept at constant temperature and pressure. At steady state there is a net flux of component $A$ away from the evaporating surface and component $B$ is stagnant.

The basic differential equations of momentum and mass are used as a starting point in establishing the concentration distribution as a function of the radial and axial directions. The $\mathbf{x}$ component of the steady-state momentum equations, in cylindrical coordinates for a fluid with constant properties, as given by Bird et al, ${ }_{9}^{6}$ is

$$
\begin{aligned}
\rho\left[v \frac{\partial u}{\partial r}\right. & \left.+\frac{v \theta}{r} \frac{\partial u}{\partial \theta}+u \frac{\partial u}{\partial x}\right]=\frac{\partial p}{\partial x} \\
& +\mu\left[\frac{1}{r} \frac{\partial}{\partial r}\left(r \frac{\partial u}{\partial r}\right)+\frac{1}{r^{2}} \frac{\partial^{2} u}{\partial \theta^{2}}+\frac{\partial^{2} u}{\partial x^{2}}\right] .
\end{aligned}
$$

If one assumes there is no axial pressure gradient and that the axial and azimuthal vejocities are negligible this equation becomes

$$
u \cdot \frac{\partial u}{\partial x}=v \frac{1}{r} \cdot \frac{\partial}{\partial x}\left(x \frac{\partial u}{\partial r}\right)+v \frac{\partial^{2} u}{\partial x^{2}}
$$

The assumption that $\frac{\partial p}{\partial x}$ is negligible is verified by later calculations. 
Gas B stream $\longrightarrow$

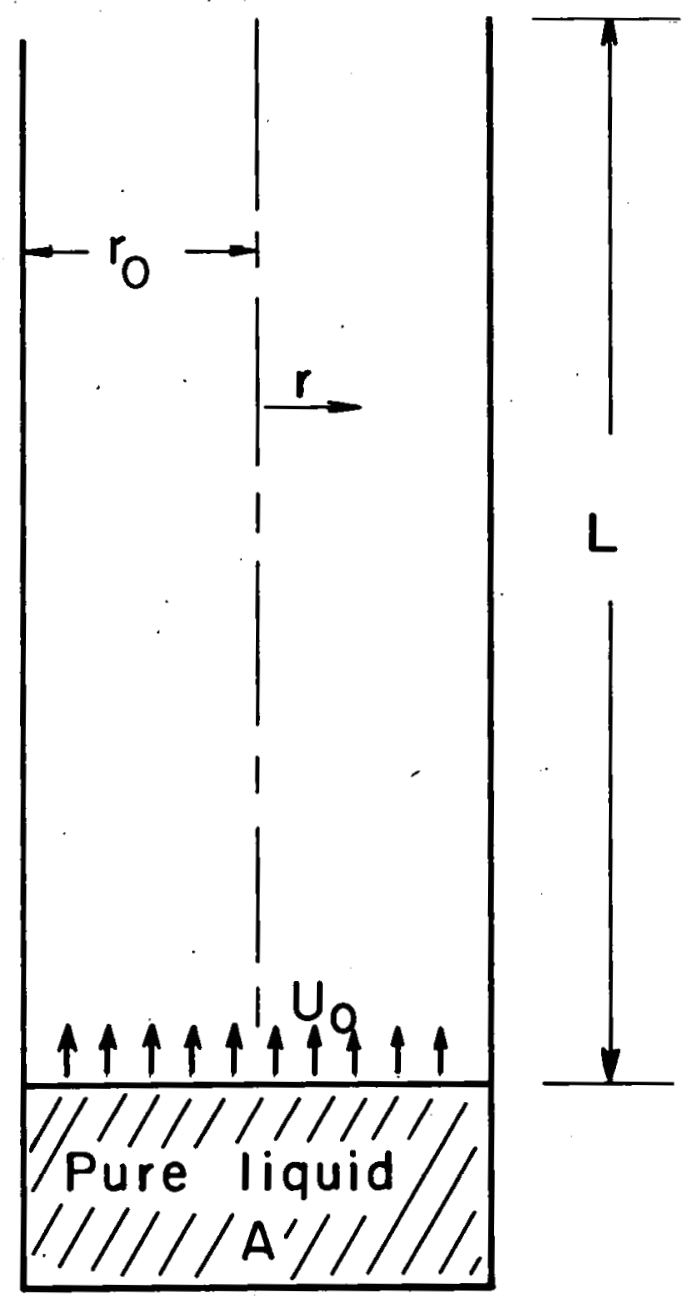

MU. 28120

Fig. 1. Schematic diagram of the theoretical model. 
The corresponding steady-state diffusion equation for com: ponent $A$ with a constant diffusion coefficient and.'density is ${ }^{7}$

$$
u \frac{\partial C_{A}}{\partial x}=D \frac{1}{r} \frac{\partial}{\partial r}\left(r \frac{\partial C_{A}}{\partial r}\right)+D \frac{\partial^{2} C_{A}}{\partial x^{2}}
$$

Equation (6) results from the application of conservation 'of mass and Fick's first law.

Now consider the boundary values of the system:

1. The concentration of $A$ at the liquid-gas interface is constant. Hence

$$
C_{A}=C_{S} \text {, a constant at } x=0 \text { for all } r \text {. }
$$

2. The concentration of $A$ at the top of the tube is zero. Hence

$$
C_{A}=0 \quad \text { at } x=L \text { for all } r
$$

3. The concentration profile is axially symmetric. Hence

$$
\frac{\partial C_{A}}{\partial r}=0 \quad \text { at } r=0 \text { for all } x \text {. }
$$

4. There is no transfer from the walls of the tube into the gas. Hence

$$
\frac{\partial C_{A}}{\partial r}=0 \quad \text { at } r=r_{0} \text { for all } x_{\text {. }}
$$

5. There is no slip at the wall. Hence

$$
u=0 \quad \text { at } r=r_{0} \text { for all } x \text {. }
$$

6. The velocity profile is axially symmetric. Hence

$$
\frac{\partial u}{\partial r}=0 \quad \text { at } r=0 \text { for all } x \text { 。 }
$$

7. At the evaporating surface the diffusion velocity is related to the concentration gradient of the diffusing species by

$$
\therefore \quad u=-\frac{D}{C_{B}}\left(\frac{\partial C_{A}}{\partial x}\right) \quad \text { at } x=0 \text { for all } r
$$

The above boundary conditions apply to the functions $C(x, r)$ and $u(x, r)$. Boundary condition 7 couples the convection equation (5) and the diffusion equation (6). This boundary condition is obtained from Eq: (3). 
The above equations assume that the mass average velocity is equal to the mole average velocity. This is true only when the molecular weight of $A$ equals that of $B$. However, for low mass-transfer rates the assumption introduces little error and is satisfactory.

Since the form of the hydrodynamic velocity, $u_{0}$, in the tube is not known, several approximations are made and discussed.here. First an average uniform hydrodynamic velocity $u_{0}$ over the tube cross section is assumed, and the solution to the diffusion equation (6) is achieved.

The solution of the diffusion equation (6) that satisfies the boundary conditions $1,2,3$, and 4 is

$$
C_{0}=C_{S}\left[\frac{1-\exp \left[\left(u_{0} / D\right)(L-x)\right]}{1-\exp \left[\left(u_{0} / D\right) L\right]}\right] \text {. }
$$

Equation (7) is equivalent to Eq. (4) and both can be used to calculate either the mass flux or.the concentration profile.

Now. the magnitude of the assumed velocity $u_{0}$ can be established by applying boundary condition 7 to Eq. (7). Then

$$
u_{0}=-\frac{D}{C_{B}}\left(\frac{\partial C_{0}}{\partial x}\right)_{x=0}
$$

Hence

$$
u_{0}=\frac{D}{L} \ln \left(1+\frac{C_{S}}{C_{B}}\right) .
$$

With $\mathrm{D}=0.11 \mathrm{~cm}^{2} / \mathrm{sec}$ and a tube length $\mathrm{L}$ of $13 \mathrm{~cm}$, the value of $\mathrm{u}_{0}$ at the total pressure of $74.8 \mathrm{~cm}$ of $\mathrm{Hg}$ and at a temperature of $35^{\circ} \mathrm{C}$ is $0.00186 \mathrm{~cm} / \mathrm{sec}$. By use of this value of $u_{0}$, the concentration distribution $C_{0}(x)$ is calculated from Eq. (7). This is plotted in Fig. 2. $C_{0}$ is seento be a nearly linear function of $\mathbf{x}$.

At this point a new velocity distribution is assumed, of the form

$$
u_{.}=u_{0}+u_{.}
$$




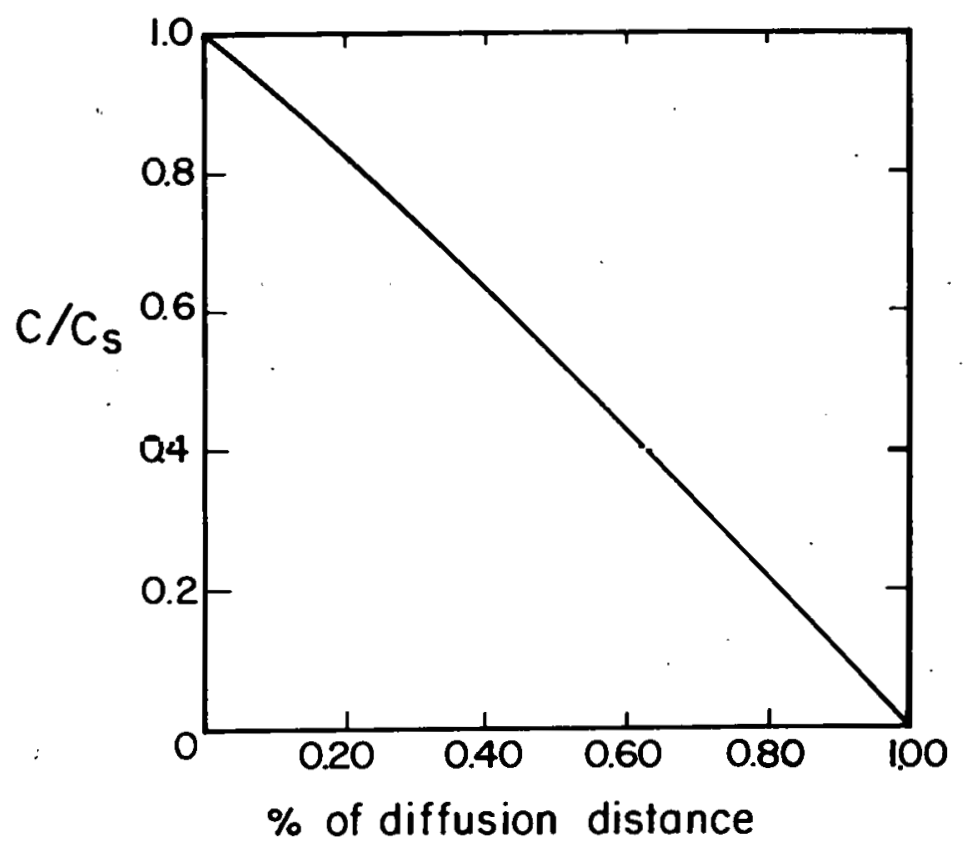

MU.28121

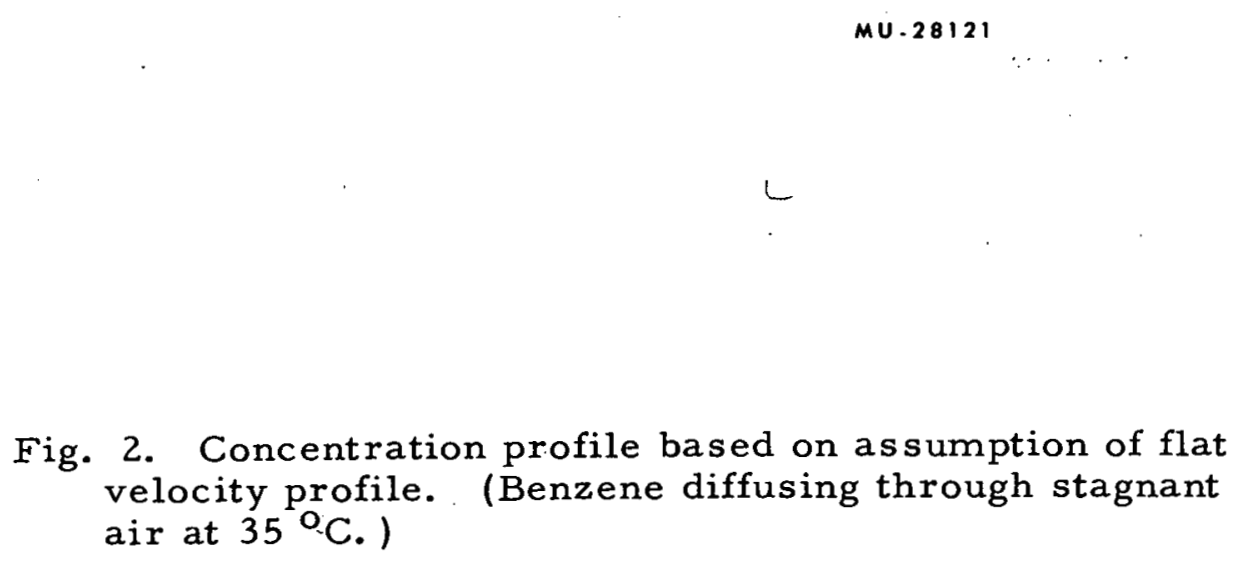


where $u_{1}(x, r)$ represents a perturbation in the previously assumed uniform hydrodynamic velocity, $u_{0}$ 。

Substituting Eq. (9) into (5) gives

$$
\begin{aligned}
& \left(u_{0} \frac{\partial \underline{u}_{0}}{\partial x}+u_{1} \frac{\partial u_{0}}{\partial x}\right)+\left(u_{0} \frac{\partial u_{1}}{\partial x}+u_{1} \frac{\partial u_{1}}{\partial x}\right) \\
& =v\left[\frac{\partial^{2} u_{0}}{\partial r^{2}}+\frac{1}{r} \frac{\partial u_{0}}{\partial r}+\frac{\partial^{2} u_{0}}{\partial x^{2}}\right]+v\left[\frac{\partial^{2} u_{1}}{\partial r^{2}}+\frac{1}{r} \frac{\partial u_{1}}{\partial r}+\frac{\partial^{2} u_{1}}{\partial x^{2}}\right] .
\end{aligned}
$$

Since $u_{0}$ is a constant, Eq. (10) becomes

$$
u_{0} \frac{\partial u_{1}}{\partial x}+u_{1} \frac{\partial u_{1}}{\partial x}=v\left[\frac{\partial^{2} u_{1}}{\partial r^{2}}+\frac{1}{r} \frac{\partial u_{1}}{\partial r}+\frac{\partial^{2} u_{1}}{\partial x^{2}}\right] \text {. }
$$

The term $u_{1} \frac{\partial u_{1}}{\partial x}$ is of second order and can be neglected. One obtains, from Eq. (11),

$$
u_{0} \frac{\partial u_{1}}{\partial x}=v\left[\frac{\partial^{2} u_{1}}{\partial r^{2}}+\frac{1}{r} \frac{\partial u_{1}}{\partial x}+\frac{\partial^{2} u_{1}}{\partial x^{2}}\right] \text {. }
$$

The diffusion system under consideration is characterized by very slow motion flow. Since the inertia forces are proportional to the square of the velocity, whereas the viscous forces are proportional to its first power, the inertia.term may be neglected as suggested by Schlichting, 8 and Eq. (12) rearranges into

$$
v\left[\frac{\partial^{2} u_{1}}{\partial r^{2}}+\frac{1}{r} \frac{\partial u_{1}}{\partial r}+\frac{\partial^{2} u_{1}}{\partial x^{2}}\right]=0 \text {. }
$$

Since $u_{0}$ is a constant the substitution $u=u_{1}+u_{0}$ may be made for $u_{1}$ in Eq: (13), giving

$$
\frac{\partial^{2} u}{\partial r^{2}}+\frac{1}{r} \cdot \frac{\partial u}{\partial r}+\frac{\partial^{2} u}{\partial x^{2}}=0
$$


The boundary, conditions are

1. - No slip at the wall, or

$$
u=u_{1}+u_{0}=0 \quad \text { at } r=r_{0} \text { for all } x_{0}
$$

2. The perturbation, $u_{1}$, must be zero at $x=0$ :

$$
u_{1}=0 \quad \text { at } x=0 \text { for all } r \text { 。 }
$$

3. Since the system is axially symmetric,

$$
\frac{\partial u}{\partial r}=0 \quad \text { at } r=0 . \text { for all } x_{0}
$$

4. The last: boundary condition is obtained from the equation of continuity。 At $x=0$. the radial velocity is zero. Thus

$$
\frac{\partial u}{\partial x}=0 \quad \text { at } x=0 \text { for all } r \text { 。 }
$$

The equation may now be solved by the method of Separation of Variables. Assume that the solution of Eq. (14) is of the form

$$
\mathrm{u} .=\mathrm{X}(\mathrm{x}) \mathrm{R}(\mathrm{x})
$$

when Eq. (15) is substituted in Eq. (14), there result two differential equations,

$$
\frac{d^{2} x}{d x^{2}}-\frac{a^{2}}{y} x=0
$$

and

$$
\frac{d^{2} R}{d r^{2}}+\frac{1}{r} \frac{d R}{d r}+\frac{a^{2}}{y} R=0
$$

where $a$ is a constant to be determined by the boundary. conditions. The solution of Eq. (16) is

$$
x=A \cos \sqrt{\frac{a^{2}}{v}} x+B \sin \sqrt{\frac{a^{2}}{v}} x .
$$

Equation (1.7) is one form of Bessel's equation, and has solutions of the form

$$
R=A^{\prime} J_{0}\left(\sqrt{\frac{a^{2}}{v}} r\right)+B^{\prime} Y_{0}\left(\sqrt{\frac{a^{2}}{y}} r\right)
$$


where $A, A^{\prime}, B$, and $B^{\prime}$ are constants to be determined by the boundary conditions. $J_{0}$ and $Y_{0}$ are zero-order Bessel functions of the first and second kinds. Applying boundary condition 3 gives $B^{\prime}=0$, and Eqs: (18) and (19) are combined to obtain the solution..for $u$ :

$$
u=\left(A \cos \sqrt{\frac{a^{2}}{v}} x+B \sin \sqrt{\frac{a^{2}}{v}} x\right) J_{0}\left(\sqrt{\frac{a^{2}}{v} r}\right) .
$$

The application of boundary condition 1 requires a slight modification of the definition of $u_{0^{\circ}}$. Initially $u_{0}$ had been defined as being constant over the whole cross-sectional area. However, $u_{0}$ must be zero at the wall $\left(r=r_{0}\right)$. Thus, for $u_{0}$ one can write

$$
\mathrm{u}_{0}=\sum_{\mathrm{n}} \cdot \mathrm{E}_{\mathrm{n}} \mathrm{J}_{0}\left(\beta_{\mathrm{n}} \frac{\mathrm{r}}{\mathrm{r}_{0}}\right) \text {, }
$$

where the $E_{n}{ }^{\prime}$ 's are chosen so that $u_{0}$ has a constant value for all $r$ except for $r=r_{0}$, where $u_{0}=0$. Then, when boundary condition 1 is applied. both $u_{1}$ and $u_{0}$ are zero at $r=r_{0^{\circ}}$. The values. of $E_{n}$ are found through the orthogonality relationships.

Using boundary condition 1 . on Eq. (20) requires $\sqrt{\frac{a^{2}}{v}} r_{0}=\beta_{n}$, which is a root of $\mathrm{J}_{0^{\circ}}$. Hence

$$
u=u_{1}+u_{0}=\left(A_{n} \cos \beta_{n} \cdot \frac{x}{r_{0}}+B_{n} \sin \beta_{n} \frac{x}{r_{0}}\right) J_{0}\left(\beta_{n} \frac{r}{r_{0}}\right) .
$$

Applying boundary! condition 4 requires $B_{n}=0$ 。

Therefore

$$
u_{1}=-u_{0}+A_{n} \cos \beta_{n} \cdot \frac{x}{r_{0}} \cdot J_{0}\left(\beta_{n} \frac{r}{r_{0}}\right) \text {. }
$$

Now, applying boundary condition 2, one has

$$
\left.u_{1}\right|_{x=0}=0=-u_{0}+\sum_{n} A_{n} J_{0}\left(\beta_{n} \frac{r}{r_{0}}\right) \text {. }
$$


Substituting Eq. (21) for $u_{0}$ and comparing terms shows

Hence

$$
\mathrm{E}_{\mathrm{n}}=\mathrm{A}_{\mathrm{n}}
$$

$$
u=\sum_{n} E_{n} \cdot \cos \beta_{n} \frac{x}{r_{0}} J_{0}\left(\beta_{n} \frac{r}{r_{0}}\right)
$$

This is the complete solution for the velocit $y_{8}$. $u$.

Using the orthogonality relationships of the Bessel functions provides a means of evaluating $E_{n}$ according to the relationship

$$
E_{n}=\frac{u_{0} \int_{0}^{r_{0}} r J_{0}\left(\beta_{n} \frac{r}{r_{0}}\right) d r}{\int_{0}^{r_{0}} r J_{0}^{2}\left(\beta_{n} \cdot \frac{r}{r_{0}}\right) d r}
$$

The integrals in Eq. (26) are given in Carslaw and Jaeger. 9. When Eq: $(26)$ is evaluated there results

$$
E_{n}=\frac{2 u_{0}}{\beta_{n} J_{1}\left(\beta_{n}\right)}
$$

\section{Solution of the Concentration Distribution}

The concentration distribution is calculated by using the velocity distribution given by Eq。 (25) in the diffusion equation (6). Assume now a perturbation, $\mathrm{C}_{1}$, in the concentration such that

$$
\mathrm{C}=\mathrm{C}_{0}+\mathrm{C}_{1} \text {, }
$$

where $C_{0}$ is given by Eq. (7). Substituting Eqs. (9) and (28) into Eq. (6) gives

$$
\begin{aligned}
& \left(u_{0} \frac{\partial C_{0}}{\partial x}+u_{1} \frac{\partial C_{0}}{\partial x}\right)+\left(u_{0} \frac{\partial C_{1}}{\partial x}+u_{1} \frac{\partial C_{1}}{\partial x}\right) \\
& =D\left\{\frac{\partial^{2} C_{0}}{\partial r^{2}}+\frac{1}{r} \frac{\partial C_{0}}{\partial r}+\frac{\partial^{2} C_{d}}{\partial x^{2}}\right\}+D\left\{\frac{\partial^{2} C_{1}}{\partial r^{2}}+\frac{1}{r} \frac{\partial C_{1}}{\partial r}+\frac{\partial^{2} C_{1}}{\partial r^{2}}\right\}
\end{aligned}
$$


Rearranging and neglecting the second-order term $u_{1} \frac{\partial C_{1}}{\partial x}$, gives $\left\{u_{0} \frac{\partial C_{0}}{\partial x}-D\left(\frac{\partial^{2} C_{0}}{\partial r^{2}}+\frac{1}{r} \frac{\partial C_{0}}{\partial r}+\frac{\partial^{2} C_{0}}{\partial x^{2}}\right)\right\}$

$$
+\left\{u_{0} \frac{\partial C_{1}}{\partial x}+u_{1} \frac{\partial C_{0}}{\partial x}-D\left(\frac{\partial^{2} C_{1}}{\partial r^{2}}+\frac{1}{r} \frac{\partial C_{1}}{\partial r}+\frac{\partial^{2} C_{1}}{\partial x^{2}}\right)\right\}=0 .
$$

The first term contains only $C_{0}$ and is, thus, only a function of $x$, while the second term is a function of $x$ and $r_{0}$. Thus each term must equal zero. The solution to the first.term is immediately given by Eq. (7). Then, the equation to be solved is

$$
D \frac{\partial^{2} C_{1}}{\partial x^{2}}-u_{0} \frac{\partial C_{1}}{\partial x}+D\left(\frac{\partial^{2} C_{1}}{\partial r^{2}}+\frac{1}{r} \frac{\partial C_{1}}{\partial r}\right)=u_{1} \frac{\partial C_{0}}{\partial x} .
$$

Equation (30) is to be solved with the boundary conditions
1. $\mathrm{C}_{1}=0$ at $x=0$, for all $r$,
2. $\mathrm{C}_{1}=0$ at $x=L$, for all $r$,
3. $\frac{\partial C_{1}}{\partial r}=0$ at $r=0$, for all $x$,
4. $\frac{\partial C_{1}}{\partial r}=0$
at $\mathbf{r}=\mathbf{r}_{0}$ for all $\mathrm{x}_{\text {。 }}$

Boundary condition 1 results because the perturbation must be zero initially. Condition 2 follows from the statement of the problem, since $C$ is given as zero at $x=L$, and $C_{0}$ is also zero at $x=L$ 。 Boundary conditions 3 and 4 result, respectively, from the symmetry of the problem and from the impermeability of the wall to mass flow.

From boundary conditions 3 and 4 one is led to try a solution of. the form

$$
c_{1}=\sum_{k} a_{k}(x) J_{0}\left(\lambda_{k} \underset{0}{\stackrel{r}{r}}\right)
$$

where $\lambda_{k}$ is a root of $J_{1}$. 
Differentiation of Eq. (31) and substitution into Eq. (30) yields

$$
\begin{gathered}
D \sum_{k} a_{k}^{\prime \prime}(x) J_{0}\left(\frac{\lambda_{k}}{r_{0}} r\right)-u_{0} \sum_{k} a_{k}^{\prime}(x) J_{0}\left(\frac{\lambda_{k}}{r_{0}} \cdot r\right) \\
-D \sum_{k} a_{k}(x)\left(\frac{\lambda_{k}}{r_{0}}\right) J_{0}\left(\frac{\lambda_{k}}{r_{0}} r\right) \\
=\sum_{n} E_{n} \cos \beta_{n} \frac{x}{r_{0}} J_{0}\left(\beta_{n} \frac{r}{r_{0}}\right) \frac{C_{S} u_{0}}{D} \frac{\exp \left(-u_{0} L / D+u_{0} x / D\right)}{\left[1-\exp \left(-u_{0} L / D\right)\right]}
\end{gathered}
$$

Now start with Eq. (32) and multiply both sides by $\mathrm{rJ}_{0}\left(\frac{\lambda_{\mathrm{m}}}{\mathrm{r}_{0}} \mathrm{r}\right)$ and integrate. Because of the orthogonality of the Bessel functions the only terms remaining on the left-hand side are those for $\mathrm{k}=\mathrm{m}$. Thus

$$
\begin{gathered}
D a_{m}^{\prime \prime}(x) \int_{0}^{r_{0}} r J_{0}^{2}\left(\lambda_{m} \frac{r}{r_{0}}\right) d r-u_{0} a_{m}^{\prime}(x) \int_{0}^{r_{0}} r J_{0}^{2}\left(\lambda_{m} \frac{r}{r_{0}}\right) d r \\
-D a_{m}\left(\frac{\lambda_{m}}{r_{0}}\right)^{2} \int_{0}^{r_{0}} r J_{0}^{2}\left(\lambda_{m} \frac{r}{r_{0}}\right) d r \\
=\sum_{n}\left\{E_{n} \cos \beta_{n} \frac{x}{r_{0}}\left[\int_{0}^{r_{0}} r J_{0}\left(\beta_{n} \frac{r}{r_{0}}\right) J_{0}\left(\lambda_{m} \frac{r}{r_{0}}\right) d r\right]\right\} \\
\quad \times\left\{\frac{C s_{0}^{u_{0}} \exp \left(-u_{0} L / D\right)}{D\left(1-\exp \left(-u_{0} L / D\right)\right)} \exp \left(u_{0} x / D\right)\right\} .
\end{gathered}
$$


...Upon integration of Eq. (33), one gets

$$
K_{m} a_{m}^{\prime \prime}(x)-L_{m} a_{m}^{\prime}(x)-M_{m} a_{m}^{a}(x)=\sum_{n} g_{n} f_{n}(x),
$$

where

$$
\begin{gathered}
\mathrm{K}_{\mathrm{m}}=\mathrm{D} \frac{\mathrm{r}_{0}^{2}}{2} \mathrm{~J}_{0}^{2}\left(\lambda_{\mathrm{m}}\right), \\
\mathrm{L}_{\mathrm{m}}=\mathrm{u}_{0} \frac{\mathrm{r}_{0}^{2}}{2} \mathrm{~J}_{0}^{2}\left(\lambda_{\mathrm{m}}\right), \\
\mathbf{M}_{\mathrm{m}}=\mathrm{D} \frac{\lambda_{\mathrm{m}}^{2}}{2} \mathrm{~J}_{0}^{2}\left(\lambda_{\mathrm{m}}\right), \\
\mathrm{g}_{\mathrm{n}}=\mathrm{E}_{\mathrm{n}} \frac{\mathrm{C}_{\mathrm{S}_{0}} \mathrm{u}_{0}}{\mathrm{D}} \mathrm{J}_{1}\left(\beta_{\mathrm{n}}\right) \mathrm{J}_{0}\left(\lambda_{\mathrm{m}}\right)\left[\frac{\mathrm{r}_{0}^{2} \beta_{\mathrm{n}}}{\beta_{\mathrm{n}}^{2}-\lambda_{\mathrm{m}}^{2}}\right]\left[\frac{\exp \left(-\mathrm{u}_{0} \mathrm{~L} / \mathrm{D}\right)}{1-\exp \left(-\mathrm{u}_{0} \mathrm{~L} / \mathrm{D}\right)}\right]
\end{gathered}
$$

and

$$
f_{n}(x)=\cos \beta_{n} \cdot \frac{x}{r_{0}} \cdot \exp \left(u_{0} x / D\right)
$$

Since the boundary conditions on $C_{1}$ are homogeneous, the boundary conditions on $a_{m}$ are homogeneous. That is

$$
\begin{array}{lll}
a_{m}=0 & \text { at } x=0 . \\
a_{m}=0 & \text { at } x=L .
\end{array}
$$

First, Eq。 (34) is solved by assuming it is homogeneous, i. e., $\mathrm{g}_{\mathrm{n}}=0$. Then

$$
K_{m} a_{m}^{\prime \prime}(x)-L_{m} a_{m}^{\prime}(x)-M_{m}^{a}{ }_{m}(x)=0
$$

This is a homogeneous equation with constant coefficients, which has a solution

$$
a_{m}(x)=s_{m} \exp \left(b_{1} x\right)+T_{m} \exp \left(b_{2} x\right)
$$


where

$$
\begin{aligned}
& b_{1}=\frac{L+\sqrt{L^{2}+4 K M}}{2 K} \\
& b_{2}=\frac{L-\sqrt{L^{2}+4 K M}}{2 K}
\end{aligned}
$$

The constants, $b_{1}$ and $b_{2}$, are also functions of $m$.

The particular solution to Eq. (34) must now be found. This equation can be solved for each.value of n. Thus one can write

$$
\begin{gathered}
K_{m} y_{m, n}^{\prime \prime}(x)-L_{m} y_{m, n}^{\prime}(x)-M_{m} y_{m, n}(x) \\
=g_{m, n} \cos \beta_{n} \frac{x}{r_{0}} \exp \left(u_{0} x / D\right) .
\end{gathered}
$$

The function $y$, is now the particular solution to the equation. From the form of the driving function, one is led to try a solution of the form 10

$$
\begin{aligned}
y_{m, n}=G_{m, n} e^{A x} \cos \beta_{n} x+H_{m, n} e^{A x} \sin B_{n} x^{\prime} & A=\frac{u_{0}}{D}, \\
\text { where } & B_{n}=\frac{\beta_{n}}{r_{0}} .
\end{aligned}
$$

For convenience the $m$ subscript. will now be dropped. However, it must be remembered that this is only the solution for a particular value of $\mathrm{m}$. If Eq. (47) ). is differentiated with respect to $x$ and the results substituted into Eq. (34), one gets 
$\left[\exp (A X) \cos B_{n} x\right]\left[K A^{2} G_{n}+2 K A B H_{n}-K B^{2} G_{n}-L A G_{n}-L B H_{n}-M G_{n}-g_{n}\right]$ $+\left[\exp (A x) \sin B_{n} x\right]\left[K A^{2} H_{n}-2 A \dot{K B G}_{n}-K B^{2} H_{n}-L A H_{n}+L B G_{n}-M H_{n}\right]=0$ 。

Now since, in general, each term must equal zero one has the relationships

$$
\begin{aligned}
& G_{n} \phi-H_{n} \gamma=g_{n} \\
& G_{n} \gamma+H_{n} \phi=0
\end{aligned}
$$

where

$$
\begin{aligned}
& \phi=K A^{2}-K B_{n}^{2}-L A-M \\
& \gamma=L B_{n}-2 K A B_{n}
\end{aligned}
$$

Solving Eqs. (49) and (50) for G and H gives .

$$
\begin{aligned}
\mathrm{H}_{n} & =-\mathrm{g}_{\mathrm{n}}\left(\frac{\gamma}{\phi^{2}+\gamma^{2}}\right) \\
\mathrm{G}_{\mathrm{n}} & =\mathrm{g}_{\mathrm{n}}\left(\frac{\phi}{\phi^{2}+\gamma^{2}}\right)
\end{aligned}
$$

$\mathrm{G}_{\mathrm{n}}$ and $\mathrm{H}_{\mathrm{n}}$ are functions of both $\mathrm{m}$ and $\mathrm{n}$. All the terms in Eqs: (51), (52), (53), and (54) are known except for $H_{n}$ and $G_{n^{*}}$ Thus these coefficients can be found:

The total solution for $\mathrm{C}_{1}$ is then found by combining the homogeneous and the particular solutions." Then one obtains $\mathrm{C}_{1}=\sum_{\mathrm{m}} \mathrm{J}_{0}\left(\frac{\lambda_{\mathrm{m}}}{\mathrm{r}_{0}} \mathrm{r}\right)\left\{\mathrm{S}_{\mathrm{m}} \exp \left(\mathrm{b}_{1} \mathrm{x}\right)+\mathrm{T}_{\mathrm{m}} \exp \left(\mathrm{b}_{2} \mathrm{x}\right)\right\}$
$+\sum_{\mathrm{m}} \mathrm{J}_{0}\left(\frac{\lambda_{\mathrm{m}}}{\mathrm{r}_{0}} \mathrm{r}\right) \exp (\mathrm{Ax})\left\{\sum_{\mathrm{n}} \mathrm{G}_{\mathrm{m}, \mathrm{n}} \cos \left(\mathrm{B}_{\mathrm{n}} \mathrm{x}\right)+\mathrm{H}_{\mathrm{m}, \mathrm{n}} \sin \left(\mathrm{B}_{\mathrm{n}} \mathrm{x}\right)\right\}$. 
Now, applying the boundary conditions

$$
\begin{array}{ll}
C_{1}=0 & \text { at } x=0 \\
C_{1}=0 & \text { at } x=L
\end{array}
$$

results in the following at $\mathrm{x}=0$

$$
0=s_{m}+T_{m}+\sum_{n} G_{m, n}
$$

or

$$
\mathbf{S}_{\mathrm{m}}+\mathbf{T}_{\mathrm{m}}=-\sum_{\mathbf{n}} \mathrm{G}_{\mathrm{m}, \mathrm{n}} .
$$

At $\mathrm{x}=\mathrm{L}$ one gets;

$0=S_{m} \exp \left(m_{1} L\right)+T_{m} \exp \left(m_{2} L\right)+\exp (A L) \sum_{n} G_{m, n} \cos \left(B_{n} L\right)+H_{m, n} \sin \left(B_{n} L\right)$.

Since the se equations contain summations they cannot be solved easily to obtain explicit functions for $S$ and $T$. To obtain these, one must put in numerical values for $G_{m, n}$ and $H_{m, n^{\circ}}$. Then $C_{1}$ is calculated from Eq: (55).

Equation (25) was used to calculate the velocity profile, using the first two eigenvalues. Convergence of the series was tested at $\mathbf{x}=0$ by using eight eigenvalues.: The results with eight eigenvalues were within $10 \%$ of $u_{0}$ for all $r$ except near $r=0$ and $r=r_{0}$. At these points even more eigenvaiues are required. The series can

$\%$... thus be seen to converge, but it converges slowly.

The concentration profile was calculated by using only the first four values of $n$ and with $m=1$. After four terms the summation in $n$ is converging very rapidly." Calculations were made for $m=2$. This gave a correction of only $10 \%$ of the value for $m=1$.

Numerical evaluation of the concentration profile shows that no significant radial concentration gradient exists. Now consider a diffusion tube with no radial concentration gradient but with some 
radial velocity distribution: Component $A$ is diffusing through stagnant component $B$. In a thin cylindrical section, which has a constant velocity $u(r)$, the mass flux is given by

$$
N_{A}=-D \frac{\partial C_{A}}{\partial x}+u(r) C_{A}
$$

This is equivalent to Eq. (3). The total mass transfer: is found by integrating over all values of $r$, or

$$
J_{T}=\int_{0}^{r_{0}} N_{A} 2 \pi r d r=2 \pi \int_{0}^{r_{0}}\left(-D \frac{d_{A}}{d x}\right) r d r+2 \pi \int_{0}^{r_{0}} C_{A} u(r) r d r .
$$

Since $C_{A}$ is not a function of $r$, one gets

or

$$
J_{T}=-D\left(\frac{\partial C_{A}}{\partial x}\right) \pi r_{0}^{2}+u_{0} \pi r_{0}^{2} \cdot C_{A}
$$

$$
\mathrm{N}_{\mathrm{A}}=\frac{\mathrm{J}_{\mathrm{T}}}{\pi \mathrm{r}_{0}^{2}}=-\mathrm{D} \frac{\partial \mathrm{C}_{\mathrm{A}}}{\partial \mathrm{x}}+\mathrm{u}_{0} \mathrm{C}_{\mathrm{A}}
$$

Equation (64). is the same equation one gets by assuming plug concentration and velocity profiles. This can be integrated.to give Eq. (4).

\section{Alternative Development for Obtaining}

\section{the Concentration and Velocity Profiles}

In the above development of the concentration and velocity equations three assumptions were made in writing the basic momentum equation:

1. $\frac{d p}{d x}$ is negligible.

2. Therc are no axial or azimuthal velocities.

3. Inertia terms may be neglected.

These assumptions seem quite valid in view of the low velocities in the system. A more rigorous method of solution is possible, however, that does not require assumptions 1 and $2_{0}$ : This method is now outlined, but not solved, since the solution is extremely difficult and probably can be solved numerically only on a computer. 
Consider the radial and axial equations of motion in cylindrical coordinates, 6

$\rho\left[v \frac{\partial v}{\partial r}+u: \frac{\partial v}{\partial x}\right]=-\frac{\partial p}{\partial r}+\mu \cdot\left[\frac{\partial}{\partial r}\left(\frac{1}{r} \frac{\partial}{\partial r}(r v)\right)+\frac{\partial^{2} v}{\partial x^{2}}\right]$

and

$\rho\left[v \cdot \frac{\partial u}{\partial r}+u \cdot \frac{\partial u}{\partial r}\right]=\frac{-\partial p}{\partial x}+\mu \cdot\left[\frac{1}{r} \cdot \frac{\partial}{\partial r}\left(r \frac{\partial u}{\partial r}\right)+\frac{\partial^{2} u}{\partial r^{2}}\right]$.

Again.it.is assumed that there.is radial symmetry $\left(v_{\theta}=0\right)$. Since this is a case of very low velocities, the inertia forces are again assumed.to be negligible. 8 . Thus

$$
\begin{aligned}
& \frac{\partial p}{\partial r}=v\left[\frac{\partial}{\partial r}\left(\frac{1}{r}: \frac{\partial}{\partial r}(r v)\right)+\frac{\partial^{2} v}{\partial x^{2}}\right], \\
& \frac{\partial p}{\partial x}=v\left[\frac{1}{r} \frac{\partial}{\partial r}\left(r \frac{\partial u}{\partial r}\right)+\frac{\partial^{2} u}{\partial x^{2}}\right] .
\end{aligned}
$$

If Eq. (6.7) is now differentiated with respect to $x$, and Eq: (68) is differentiated with respect to $r$, and the results are subtracted, one gets

$\frac{\partial}{\partial x}\left[\frac{\partial}{\partial r}\left(\frac{1}{r} \frac{\partial}{\partial r}(r v)\right)+\frac{\partial^{2} v}{\partial x^{2}}\right]=\frac{\partial}{\partial r}\left[\frac{1}{r} \frac{\partial}{\partial r}\left(r \frac{\partial u}{\partial r}\right)+\frac{\partial^{2} u}{\partial x^{2}}\right]$.

The pressureterm has been eliminated from Eq: (6.9). Now $v$ and $u$ are expressed in terms of the stream function, $\psi$, according to the following relationships from Bird, Stewart, and Lightfoot: 1

$$
\begin{aligned}
& u=-\frac{1}{r} \frac{\partial \psi}{\partial r}, \\
& v=\frac{1}{r} \cdot \frac{\partial \psi}{\partial x} .
\end{aligned}
$$


Then Eq: (69) is transformed into 11

$$
\nabla^{4} \psi=0
$$

where

$$
\nabla^{2} \equiv \frac{\partial^{2}}{\partial r^{2}}-\frac{1}{r} \cdot \frac{\partial}{\partial r}+\frac{\partial^{2}}{\partial x^{2}}
$$

and

$$
\nabla^{4} \psi \equiv \nabla^{2}\left(\nabla^{2} \psi\right)
$$

Equation (72) is a fourth-order equation in the stream function which automatically satisfies the equation of continuity.

The coupling between Eq. (72) and the diffusion equation (Eq. 6) is again provided by the relationship

$$
u=-\frac{D}{C_{B}}\left(\frac{\partial C_{A}}{\partial \mathbf{x}}\right)_{x=0}
$$

The simultaneous solution of Eqs. (72) and (6) satisfying Eq. (75) and the following boundary conditions provides the exact solutions for $u$ and $C$.in the Stefan diffusion tube.

$$
\begin{array}{ll}
u=0 \text { and } r=0 & \text { at } r=0 \quad \text { for all } x, \\
\frac{\partial u}{\partial r}=0 & \text { at } x=0 \quad \text { for all } r, \\
C=C_{s} & \text { at } x=L \quad \text { for all } r, \\
C=0 & \text { at } r=0, r_{0} \text { for all } x
\end{array}
$$




\section{OUTLINE OF EXPERIMENT}

The theory of the Steian-tube method for measuring diffusion coefficients has been briefly mentioned. More detailed discussion of this method may be found in References 12 and 13.

The experiment is carried out by placing a liquid in the bottom of the diffusion tube. The liquid evaporates and diffuses through the stagnant gas. After steady state is approximated sufficiently (which has been estimated to require less then 15 minutes ${ }^{12}$ ) a concentration profile and a related velocity profile are established in the Stefan diffusion tube。

In this study, a probe based on a thermal conductivity cell was used to measure the concentration profile. The velocities involved are so low as to be undetectable, at least with the equipmentıused,in this experinent.

The diffusion coefficient can be approximately calculated from the weight.loss of the liquid by use of Eq. (4)。. Corrections must be . applied to the calculated diffusion. coefficient to take end corrections into account. This is explained fully by Lee and Wilke。 ${ }^{12}$ The real diffusion coefficient is then obtained from

$$
\frac{1}{D}=-\left(\frac{\Delta x}{D_{R}}\right) \frac{1}{x}+\frac{1}{D_{R}},
$$

where $D_{R}$ is the real diffusion coefficient (within the limits of the plug flow approximation) and $\Delta x$ is the correction to the diffusion distance due to disturbance at the ends of the diffusion tube. 


\section{APPARATUS}

The apparatus used in this study is shown schematically in Fig. 3. A photograph of the apparatus is shown in Fig. 4. The diffusion. system is substantially the same as that used in recent measurements of diffusion coefficients and is described in detail by Getzinger. 13 However, a probe and electronic recording equipment have been added to measure the concentration profile.

\section{Diffusion System}

The diffusion unit is shown schematically in Fig. 5. . The air enters the diffusion unit through straightening vanes to eliminate turbulence before passing over the diffusion tube. The diffusion unit was constructed of brass. Leads are provided to connect the probe and the electrical measuring devices. A photograph of the equipment is shown in Fig. 6.

The diffusion tube itself was designed to give a diffusion area with $l$ in. $i . d$. A schematic of the tube and the probe is shown in Fig. 7, and a photograph of the actual equipment in Fig. 8. The diffusion tube was built with a step design. The bottom was $1-i n_{0}$.i.d.

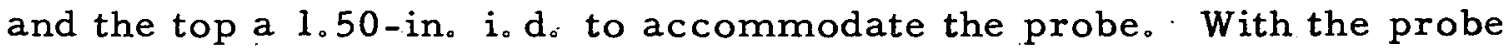
in place the top part also had a $1-$ in. $_{0}$ i. do providing a smooth diffusion tube.

The probe was not extended.to.the bottom of the diffusion tube, so that liquid was prevented from rising up between the probe and the diffusion tube wall by capillary action (preliminary experiments had shown this to be a problem).

With the probe in place the actual diffusion area was an uniform 1-in. i. d. circular cross section. An aluminum sleeve was used over the bottom of:the diffusion tube to get a uniform outside diameter of $1.535 \mathrm{in}$. This gave a tight fit within the diffusion-tube holder, providing good the rmal contact.

The diffusion tube itself was constructed with a wall thickness of only $0.018 \mathrm{in}$. This made the assembly light enough to be weighed on the analytical balance in the laboratory to determine the weight loss by evaporation during a run. 


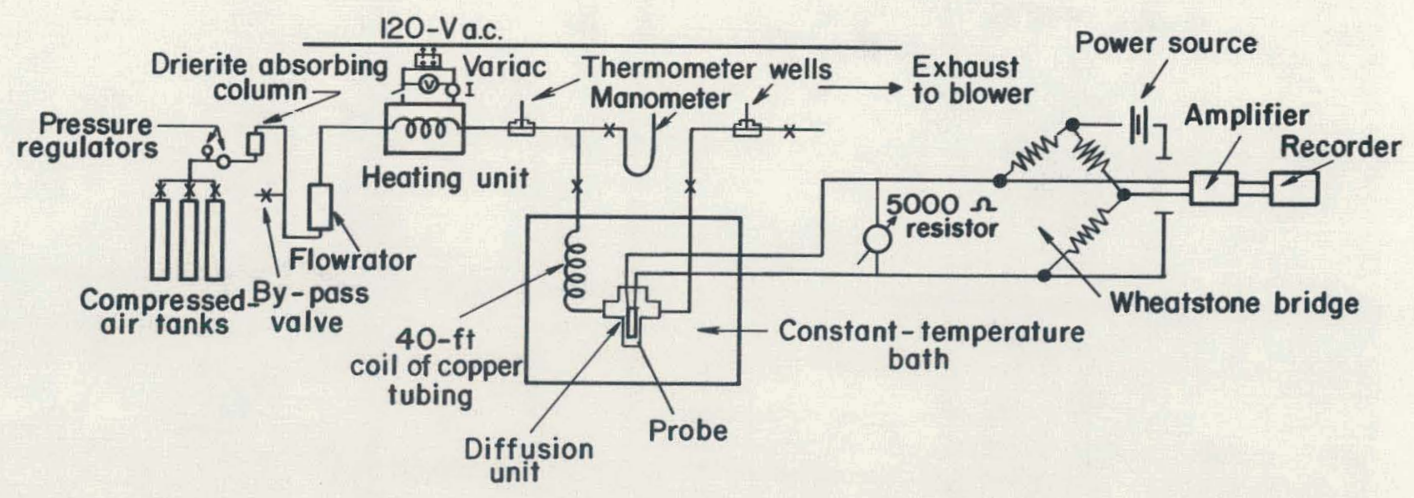

MU -28122

Fig. 3. Schematic diagram of the apparatus. 


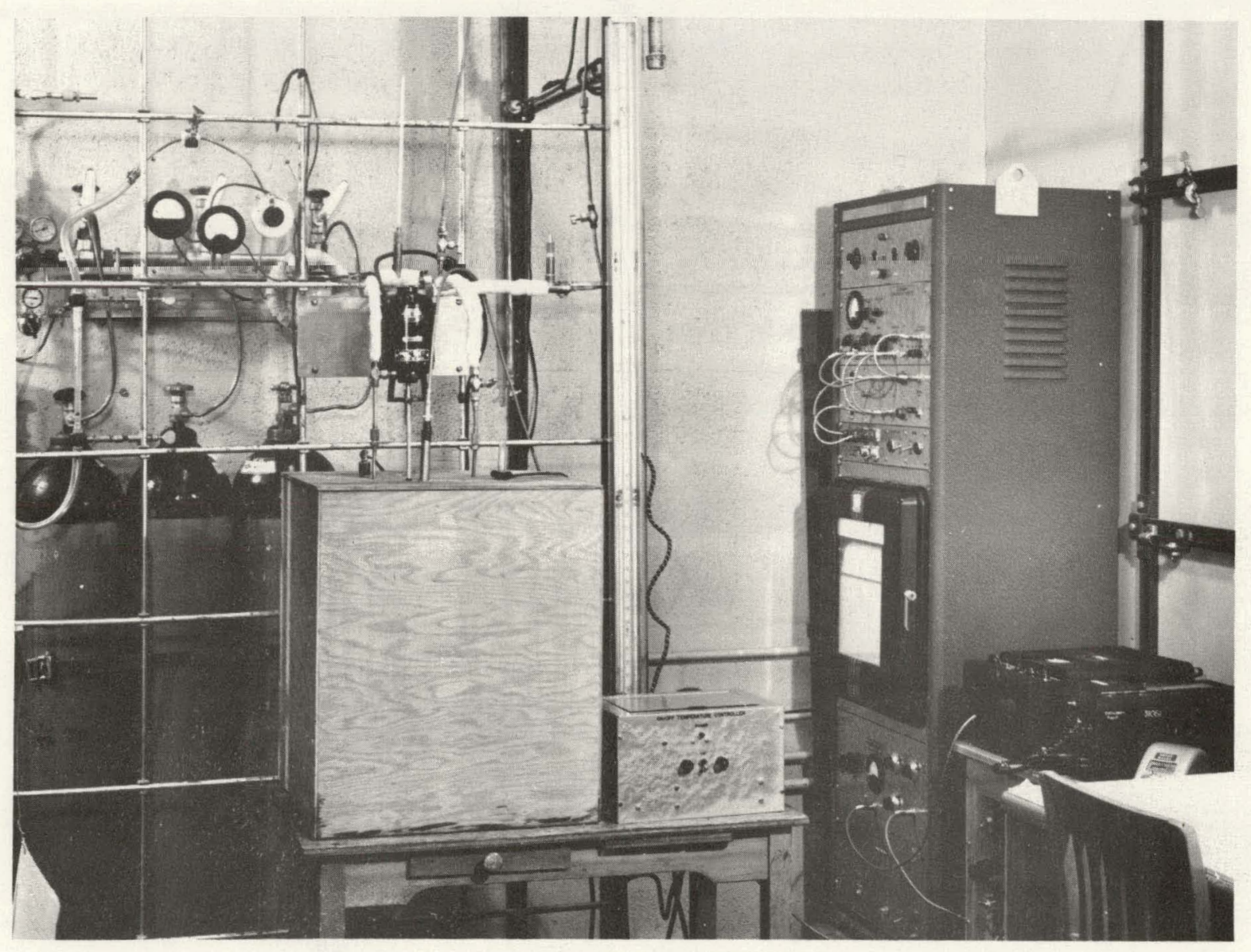

$\mathrm{ZN}-3357$

Fig. 4. View of the apparatus. 


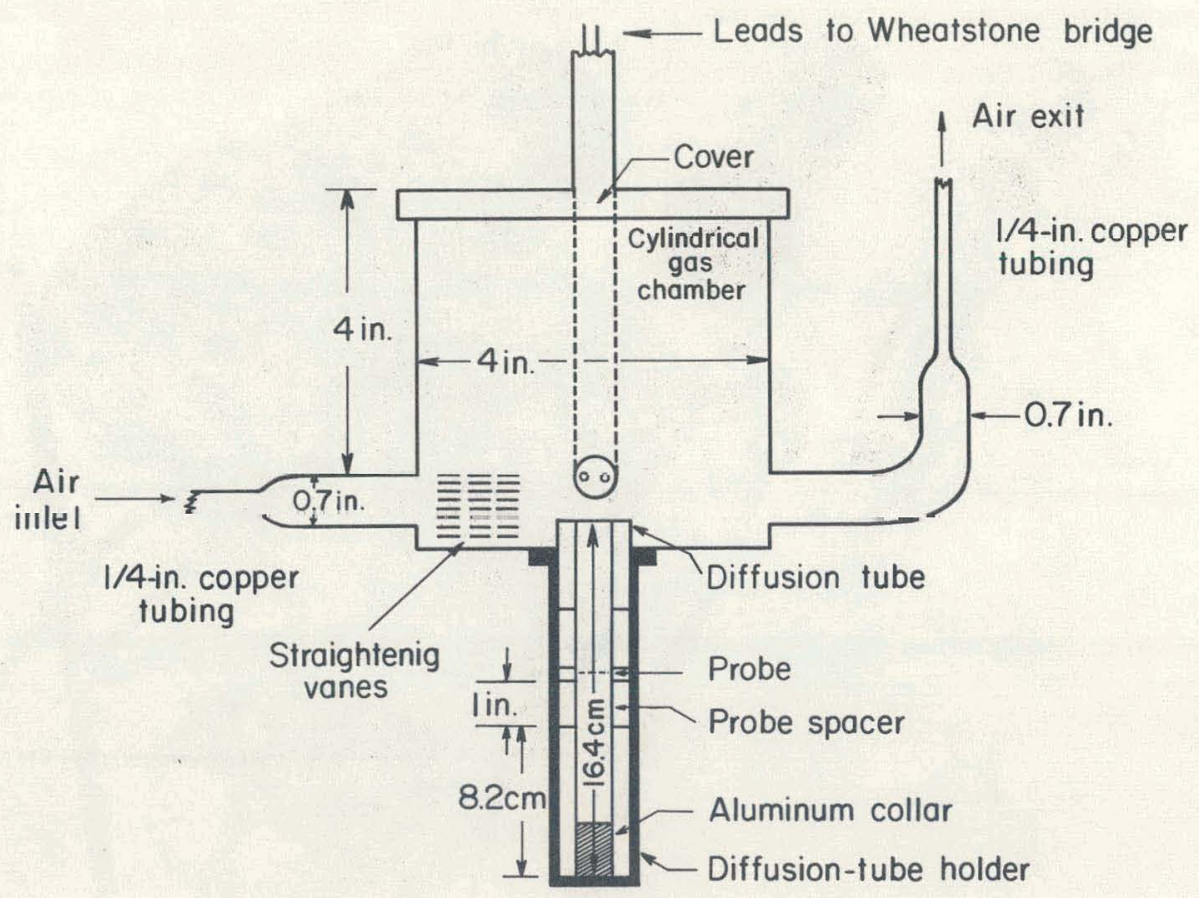

MU. 28123

Fig. 5. Diffusion unit. 


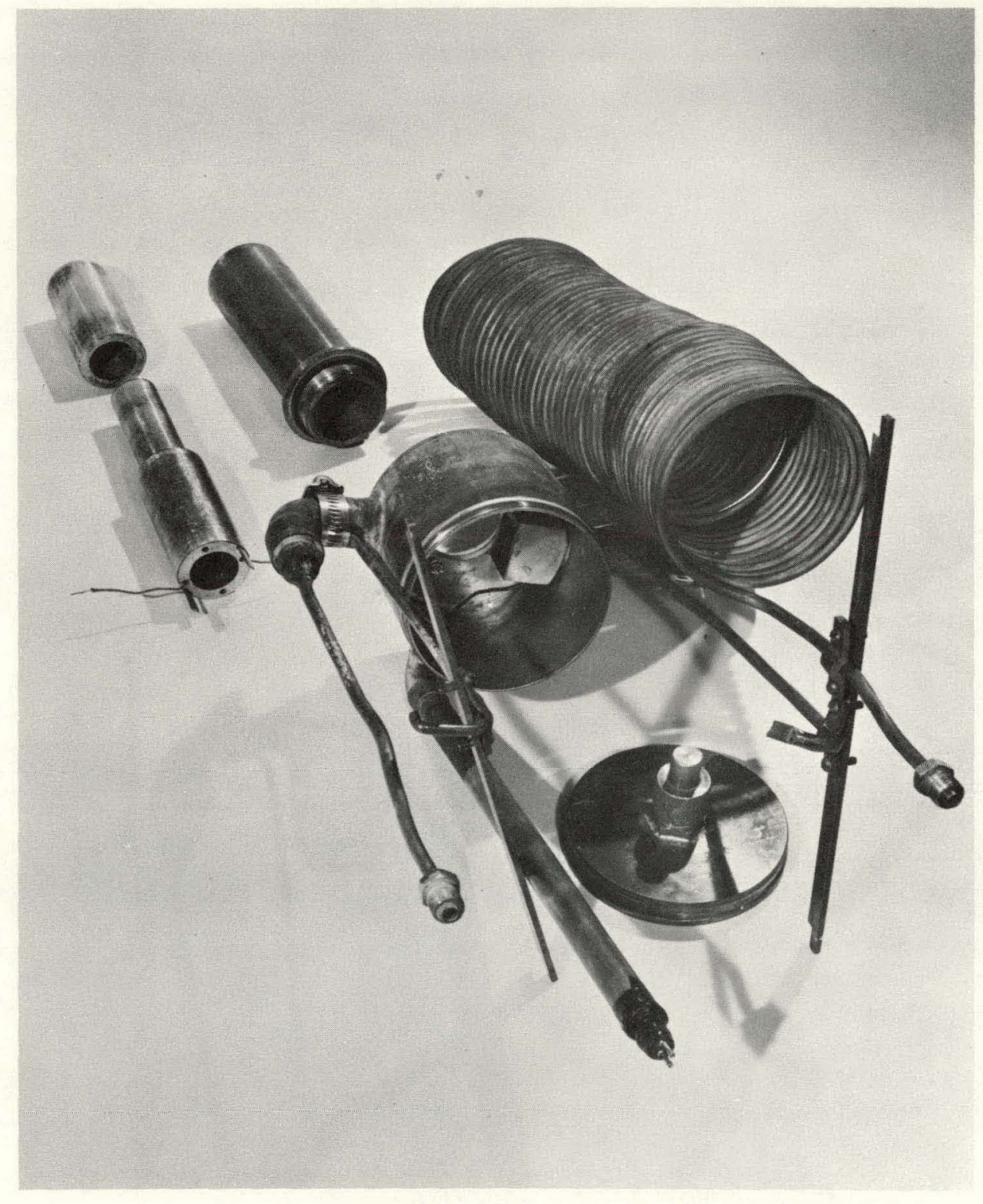

$\mathrm{ZN}-3360$

Fig. 6. Diffusion unit (exploded view). 


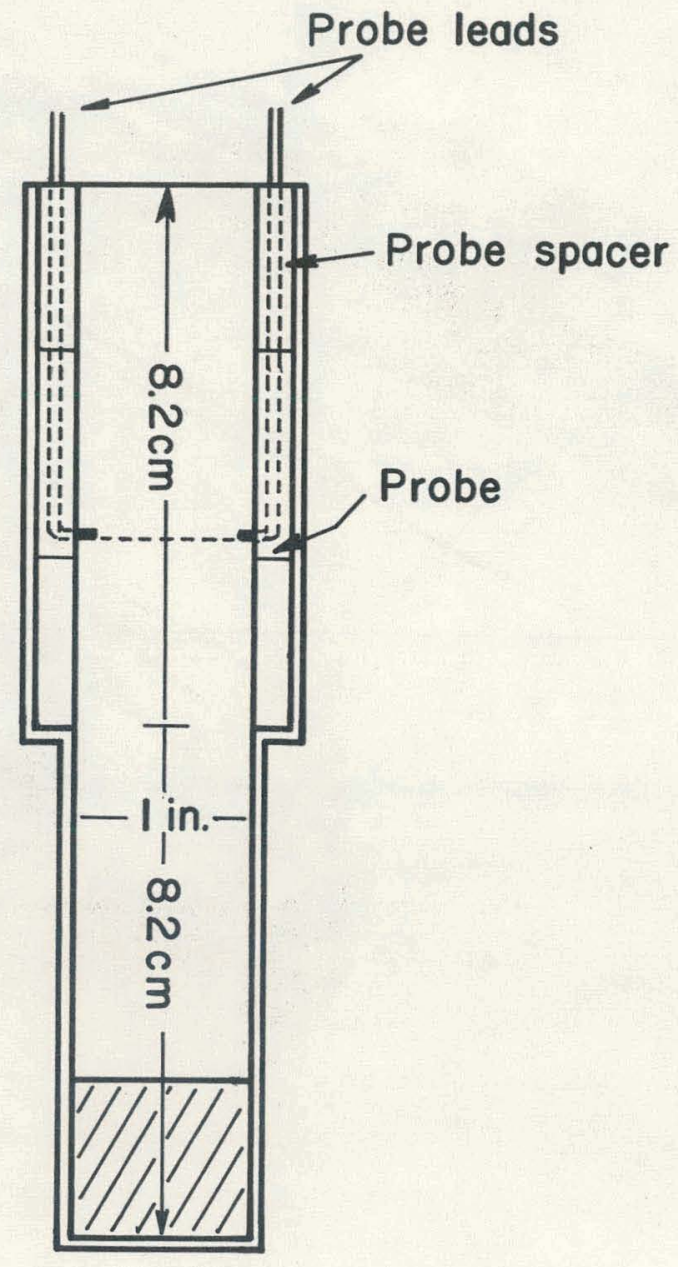

$M U-28124$

Fig. 7. Schematic drawing of diffusion tube and probe. 


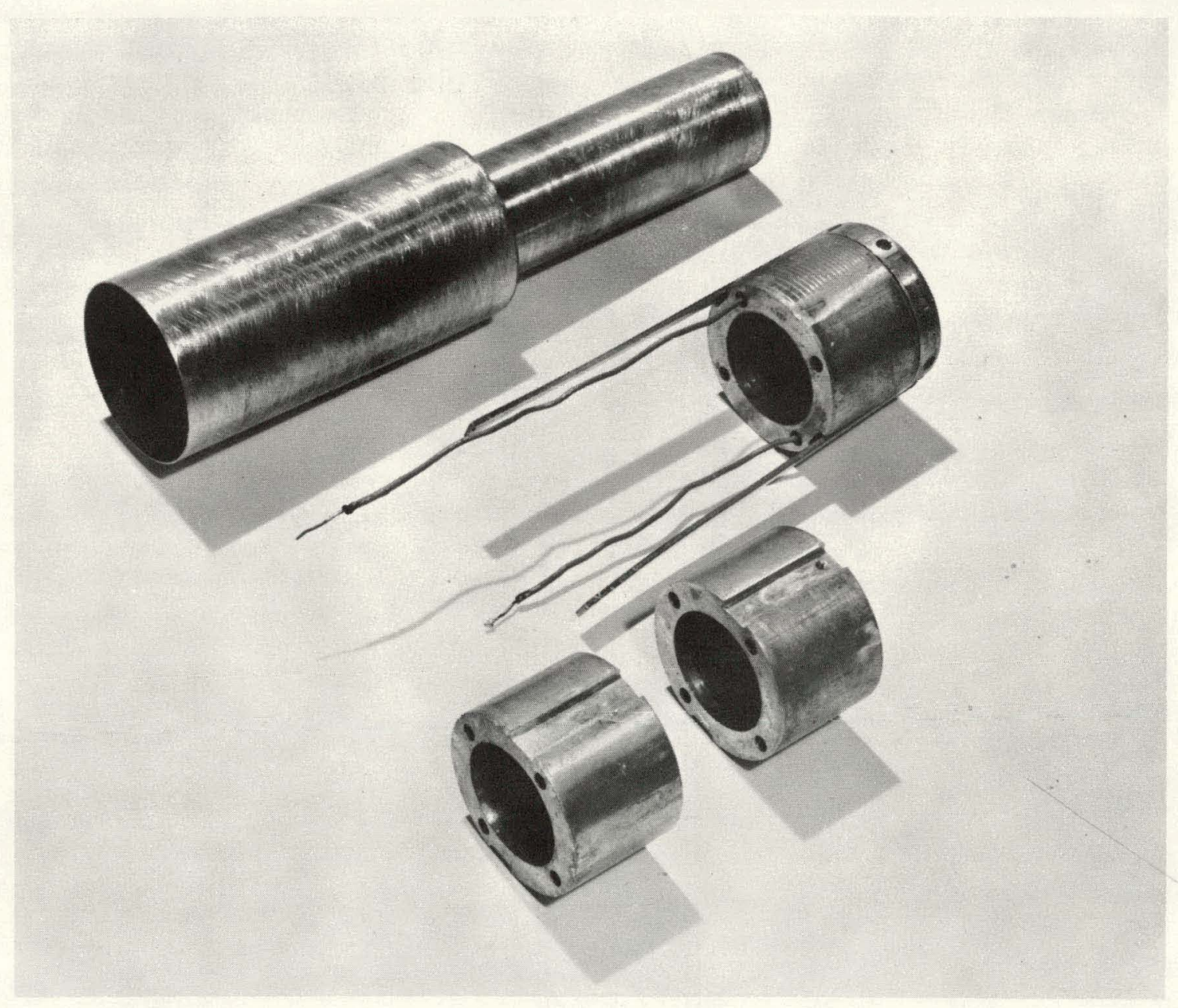

ZN-3359

Fig. 8. Diffusion tube and probe. 
Measurements were made of the time required to reach thermal equilibrium in the system. After only 15 minutes the gas temperature as measured by a conventional mercury thermometer was found to be within $0.1{ }^{\circ} \mathrm{C}$ of the bath temperatures.

Air enters the system at room temperature from compressed air cylinders through a three-stage pressure regulator. It is then dried with an isopropyl alcohol-dry ice trap and is then further dried with a 6-in. column of Drierite. After passage through a flowrator, it is heated by an electric heating element to about $32{ }^{\circ} \mathrm{C}$. The air is then passed through 40 feet of copper tubing immersed in a constanttemperature bath, where it is heated to $35.0 \pm 0.1^{\circ} \mathrm{C}$, the temperature used in the experiments. The diffusion unit is also immersed in the constant-temperature bath to insure isothermal operation. After passing through the diffusion unit the air is exhausted through a blower to the outside.

The constant-temperature bath is a 12 -in.-diameter by 16 -in.deep Pyrex jar housed in a large wooden box insulated with Styrofoam. The bath temperature is maintained at $35.0 \pm 0.1{ }^{\circ} \mathrm{C}$ by an electric heating element regulated by a mercury thermoregulator connected to a specially built controller. The temperature was chosen to give reasonably high vapor pressure for the benzene, the liquid used in the experiment. The bath is agitated by a Variac-controlled variable-speed General Electric motor driving a specially built propeller.

\section{Probe}

To measure the concentration profiles in the diffusion tube, a probe based on a thermal conductivity cell was used. An optical measuring system was considered but rejected because it would require a change in the geometry of the diffusion tube. An optical device could be used only with a flat slab for the diffusion tube, and it was desirable to maintain the geometry used in previous studies.

A brief study was made of the expected probe response to permit optimum probe design. The principle of the probe operation is the same as that of a thermal-conductivity cell. A small electric current is passed through a high-resistance thin wire. Since the 
resistance depends on the temperature of the wire, measurement of the resistance by a Wheatstone Bridge permits one to obtain the wire temperature. The wire temperature depends, in turn, on the rate of heat removal, which is a function of gas composition around the wire.

A heat balance about a differential cross section of the wire, assuming no radial temperature gradients within the wire, gives

$$
I^{2} R_{w}+\epsilon k_{w} \frac{\pi}{4} D_{w}^{2} \frac{d^{2} T_{w}}{d x^{2}}-\epsilon \pi D_{w}\left(T_{w}-T_{A}\right) h_{c}=0
$$

where $h_{c}=$ heat-transfer coefficient between the wire and the surrounding gases, $\epsilon=$ conversion factor, 4.2 joules/calorie, $\mathrm{k}_{\mathrm{w}}=$ thermal conductivity of the wire. The resistance of the wire is given by

$$
R=R_{0}\left[1+\theta\left(T-T_{0}\right]\right. \text {, }
$$

and the heat-transfer coefficient for free convection is given by ${ }^{14}$

$$
\begin{aligned}
& \frac{h_{e} D_{w}}{k_{f}}=0.47 \operatorname{Pr}^{1 / 4}\left[\frac{D_{w}^{3} \rho_{f} g \nabla\left(T_{w}{ }^{-T}{ }^{\prime}\right.}{\mu_{f}^{2}}\right]^{1 / 4} \\
& \frac{d^{2}\left(T_{w}{ }^{-T_{A}}\right)}{d^{2}}-\frac{1.88 k_{f}}{k_{w} D^{2}} \operatorname{Pr}^{1 / 4}\left(\frac{D_{w}^{3} \rho_{f} g \nabla}{\mu_{f}^{2}}\right)^{1 / 4}\left(T_{w}-T_{A}\right)^{1 / 4} \\
& +\frac{4 I^{2} R_{0} \theta}{\pi D_{w}^{2} \epsilon k} \quad\left(T_{w}-T_{A}\right)=-\left(4 I^{2} R_{0}\right) /\left(\pi D_{w}^{2} \epsilon k_{w}\right)
\end{aligned}
$$

This nonlinear differential equation must satisfy the following boundary conditions

$$
\text { 1. } \quad \frac{\mathrm{d}\left(\mathrm{T}_{\mathrm{w}}-\mathrm{T}_{\mathrm{A}}\right)}{\mathrm{dx}}=0 \quad \text { at } \mathrm{x}=0 \text {, }
$$

i. e, the temperature profile must be symmetric about the center of the wire. 
2. $T_{\mathrm{w}}-\mathrm{T}_{\mathrm{A}}=0$ at $\mathrm{x}=\mathrm{Z}$, or the temperature of the wire must be equal to the temperature of the supports at the ends.

This equation was solved numerically to give the response of the probe to changes in gas composition. With a current of $0.2 \mathrm{~A}$ the following results were obtained.

Resistance change (ohm)

$\begin{array}{ll}\frac{\text { Probe length }(\mathrm{cm})}{0.08} & \frac{0.6}{0.00015} \\ 0.000008 & 0.0062\end{array}$

The results clearly show that a longer probe is required in order to assure satisfactory sensitivity. The Wheatstone bridge circuit used in the experiment is capable of detecting resistance changes of about $0.02 \mathrm{ohm}$. Thus a total resistance change of $0.40 \mathrm{ohm}$ would be required when going from pure air to air saturated with benzene, in order to measure composition changes of $0.5 \%$ benzene.

Short probes also give a sharp high-temperature peak, whereas the longer probes give a flatter temperature profile. Thus, although the sensitivity of short probes could be increased somewhat by raising the current, this would result primarily in a higher temperature peak in the center. It was therefore decided to construct instead longer probes, giving the sensitivity required without extreme wire temperature at any point. This was accomplished by constructing semicircular probes. Because of the axial symmetry of the diffusion system these probes could still be used to measure the radial concentration gradients. Three probes were constructed, each of a different diameter. The dimensions are given in Table I. A picture of Probe 1 is shown in Fig. 9.

Table I. Probe dimensions.

\begin{tabular}{ccccc}
\hline Probe & $\begin{array}{c}\text { Nominal diameter } \\
\text { (in.) }\end{array}$ & $\begin{array}{c}\text { Maximum deviation } \\
\text { from diameter } \\
\text { (in.) }\end{array}$ & $\begin{array}{c}\text { Nominal } \\
\text { resistance } \\
\text { (ohms) }\end{array}$ \\
2 & $3 / 4$ & & $\pm 1 / 16$ & 24 \\
3 & $9 / 16$ & & $\pm 1 / 32$ & 18 \\
\hline \hline
\end{tabular}




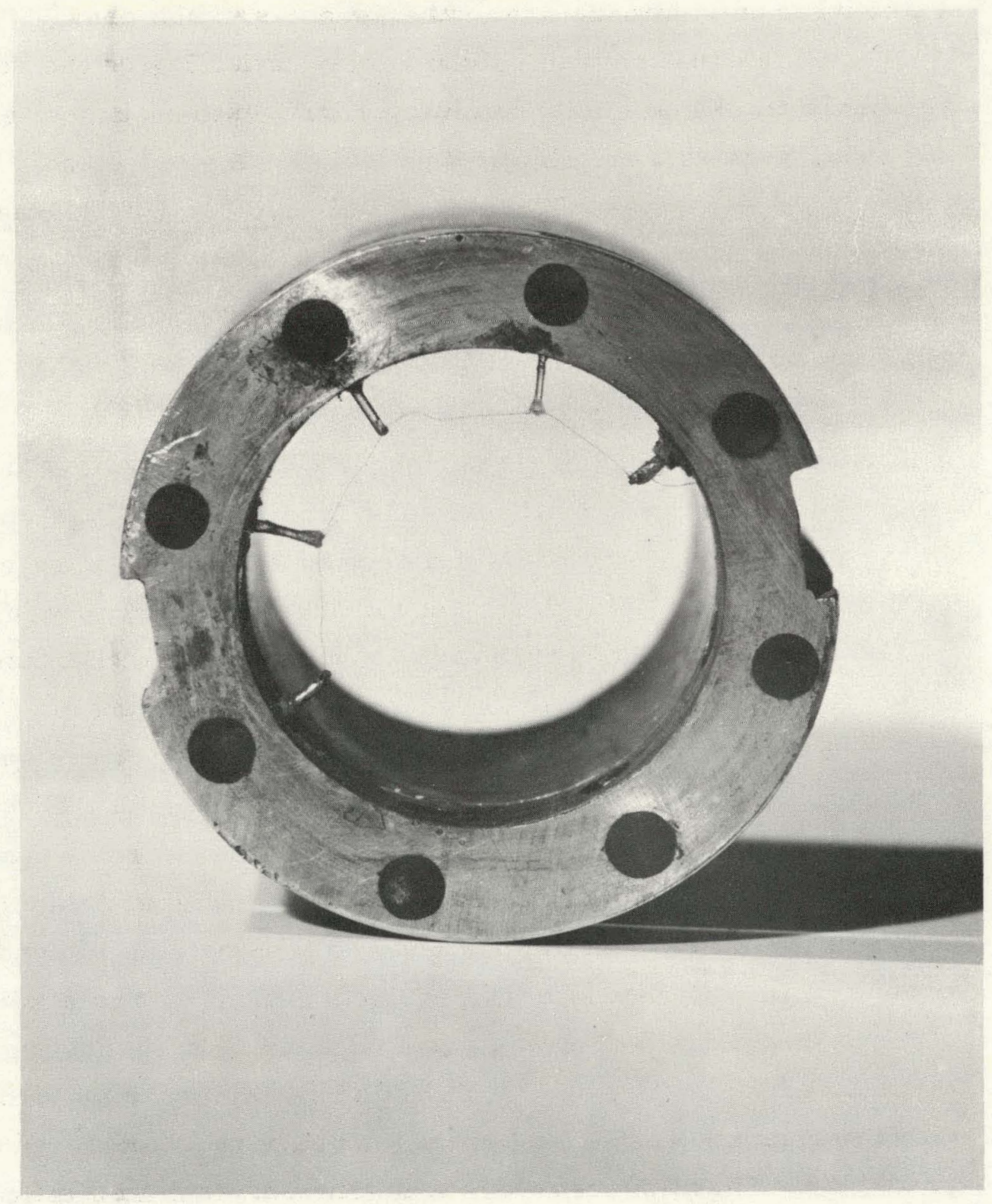

ZN-3358

Fig. 9. Probe 1. 
The probes were constructed with an aluminum ring as the primary support. The probe itself was constructed of 0.000475 -in. diameter cleaned tungsten wire obtained from the Wah Chang Corp. of New York. Thin glass capillaries were used to support the probe wire and maintain its semicircular shape. Holes were drilled in the aluminum ring to place and hold the glass supports. These were filled with an epoxy resin, Epon 828, to hold the glass in place and to provide a smooth interior surface for diffusion.

The tungsten wire was attached to the copper leads by a compression fit. A fine slit was cut in the copper leads and the tungsten wire was inserted, and then the copper wire was crimped.to secure the tungsten. . The wire was attached to the glass supports by using a small amount of "Duco" cement.

The probe was placed in the diffusion tube along with three 1-in. -high 1 -in. aluminum rings. The vertical position of the probe was changed by moving its position among these rings. All these aluminum rings had. a machined inner surface of 1 in. $i_{0} d_{0}$. in order to provide a smooth diffusion tube.

\section{Equipment for Measuring Probe Resistance}

A specially constructed dc Wheatstone bridge was used to measure the probe resistances. The signal between the two branches of the bridge, was sent to a specially built preamplifier and then to a Brush dc amplifier, Model BL-9.32, and finally to a Brush recorder, Model BL-202. A variable 5000-ohm resistor was placed in parallel with the probe. When the current to the probe was first turned on, this resistor was set at its minimum resistance, about. $10 \mathrm{omm}$, thus diverting most of the initial current surge away from the probe. Without this resistor the probes were often burned out by this initial surge. When mea'surements were to be taken the resistor was turned to its maximum value, essentially removing it from the circuit.

Probe-Calibration Cells

Three probe-calibration cells were also constructed. An effort was made to minimize adsorption of benzene in these cells, since an 
accurately known composition was desired. Therefore all seals were made either with metal-to-metal contact or with Teflon as a gasket material. A.valve for sampling the gas composition was provided. The leads to the probe were sealed with Epon 828. 


\section{EXPERIMENTAL PROCEDURE}

Benzene was chosen to be the diffusing substance and air as the gaseous diffusion medium. These were selected because considerable diffusion data have been obtained. for these components in the Stefan-tube apparatus. Also these components have considerably different thermal conductivities, thus giving a reasonably good probe sensitivity. The temperature of the system was chosen at $35^{\circ} \mathrm{C}$ to give a reasonable vapor pressure and thus a significant mass flux.

The air flow rate over the diffusion tube was chosen to give minimum end effects due to turbulence at.the top of the diffusion tube, but high enough to insure that stagnation did not take place. Preliminary experiments indicated that the air flow rate for this system should be about $120 \mathrm{cc} / \mathrm{min}$, giving a velocity of $4.65 \mathrm{~cm} / \mathrm{sec}$ through the straightening vanes in the diffusion system. This is somewhat lower than the gas rate used in recent Stefan-tube studies by Getzinger. A lower gas rate was required because of increased turbulence in the diffusion system due to the presence of the probe leads. The gas rate fixed the operating pressure at 1.6 to 2.0.in. of water above atmospheric pressure.

After the air flow rate was determined some runs were made on the system without the probe in place, in order to determine the characteristics of the system. After these runs were finished runs were made with the probe in place. Data were taken with each probe in three vertical positions. Probe resistances were measured by using a Wheatstone bridge and using the Brush amplifier and recorder to measure the bridge balance. The bridge circuit was used out of balance by a fixed amount. Figure 10 shows schematically how the apparatus was used. The balance point on the recorder was set far to the right of the recorder scale. Then all measurements were made when the Wheatstone bridge was adjusted to give a recorder reading on the left-hand side of the scale. The same point on the recorder was used for all measurements of the probe. This technique was used because it gave considerably less noise in the recorder signal. The noise ratio was greatest when the measurements of the probe resistance were made at the recorder balance point. 


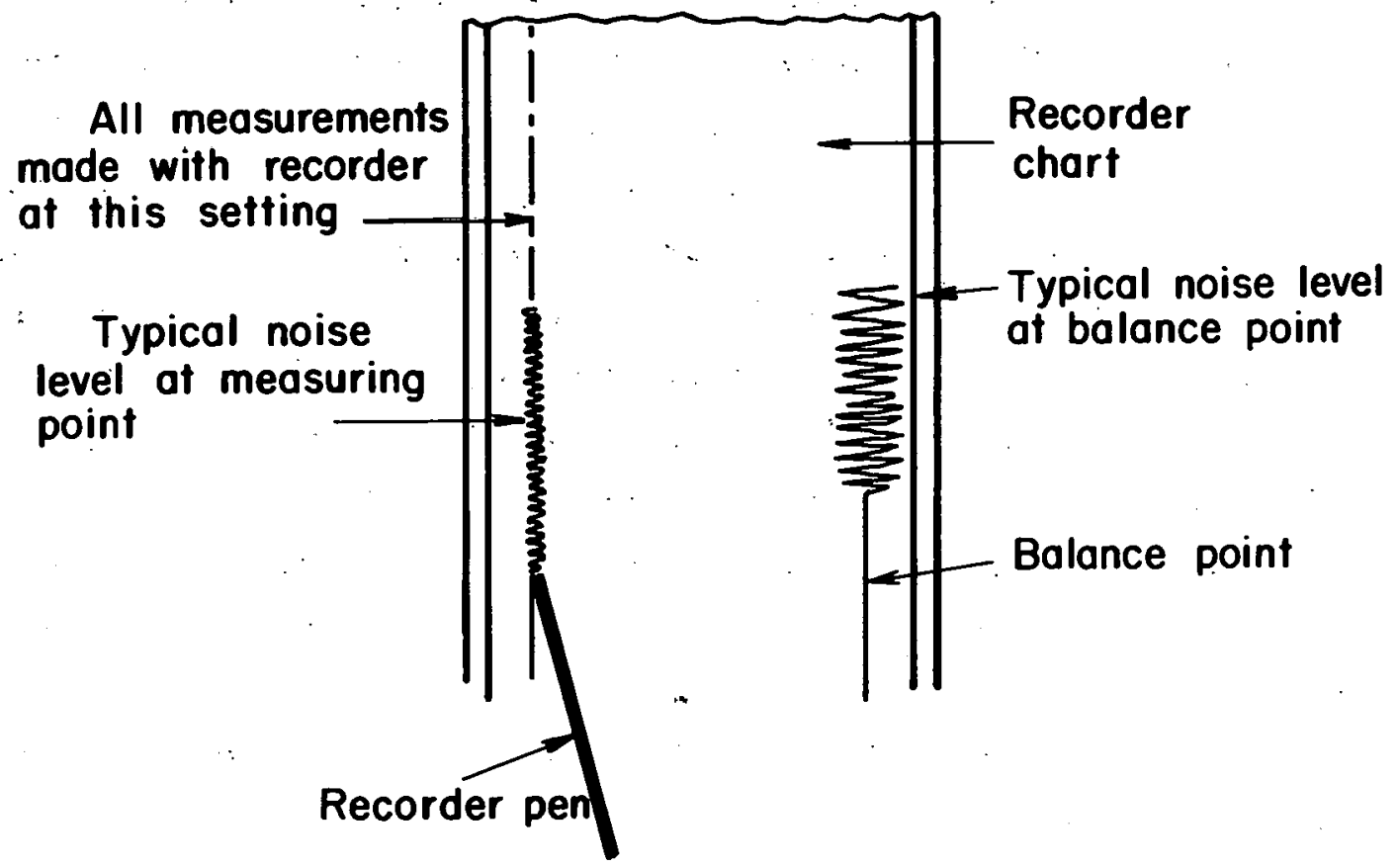

MU - 28125

Fig. 10. Schematic representation of recorder operation. 
When measurements were made on the probes the time used was as short as possible, in order to avoid setting up convection currents in the system. Several readings were made of each run, since making good electrical contacts proved to be a problem. Care was taken to make sure that the contacts were clean at all times. The lowest resistance reading of a series was picked as the true value. A precision 20-ohm wire-wound resistor was used as a standard and was measured before and after each series of runs to make sure the characteristics of the electronic equipment had not changed.

The probe resistances were adjusted when the standard resistor varied from its arbitrarily assigned value. The correction applied to the probes was obtained by measuring the apparent change in resistance of several fixed resistors (ranging from 10 to $50 \mathrm{ohms}$ ) for a deliberate change in the reading of the standard resistor. This calibration curve is shown in Fig. 11 .

The probes were calibrated in calibration cells with known gas compositions. The gas composition was determined by putting a known quantity of benzene. into the calibration cell. . The benzene was added in small glass bulbs with capillary openings. These bulbs were weighed while empty. They. were then heated and a small amount of liquid benzene was drawn in. The bulbs were sealed and reweighed, giving an accurately known sample of benzene.. In the cell the bulbs were broken and the benzene vaporized.

The gas composition in the calibration cell was then calculated. The composition was checked by a mass-spectrometer analysis of the gas to insure that adsorption in the calibration cell did not seriously alter the expected composition. The calibration cells were kept in warm water until the mass-spectrometer sample was taken, in order to prevent condensation of benzene on the walls. Duplicate massspectrometer runs were made on several samples, showing reproducibility of \pm : $0.5 \%$, Figures 12 and 13 show the gas composition in the calibration cell vs the amount of benzene added。. Cell 1 had.the gas compositions expected, but Cell 2 was lower than expected. This difference was traced to some exposed plastic insulation on the shielded 


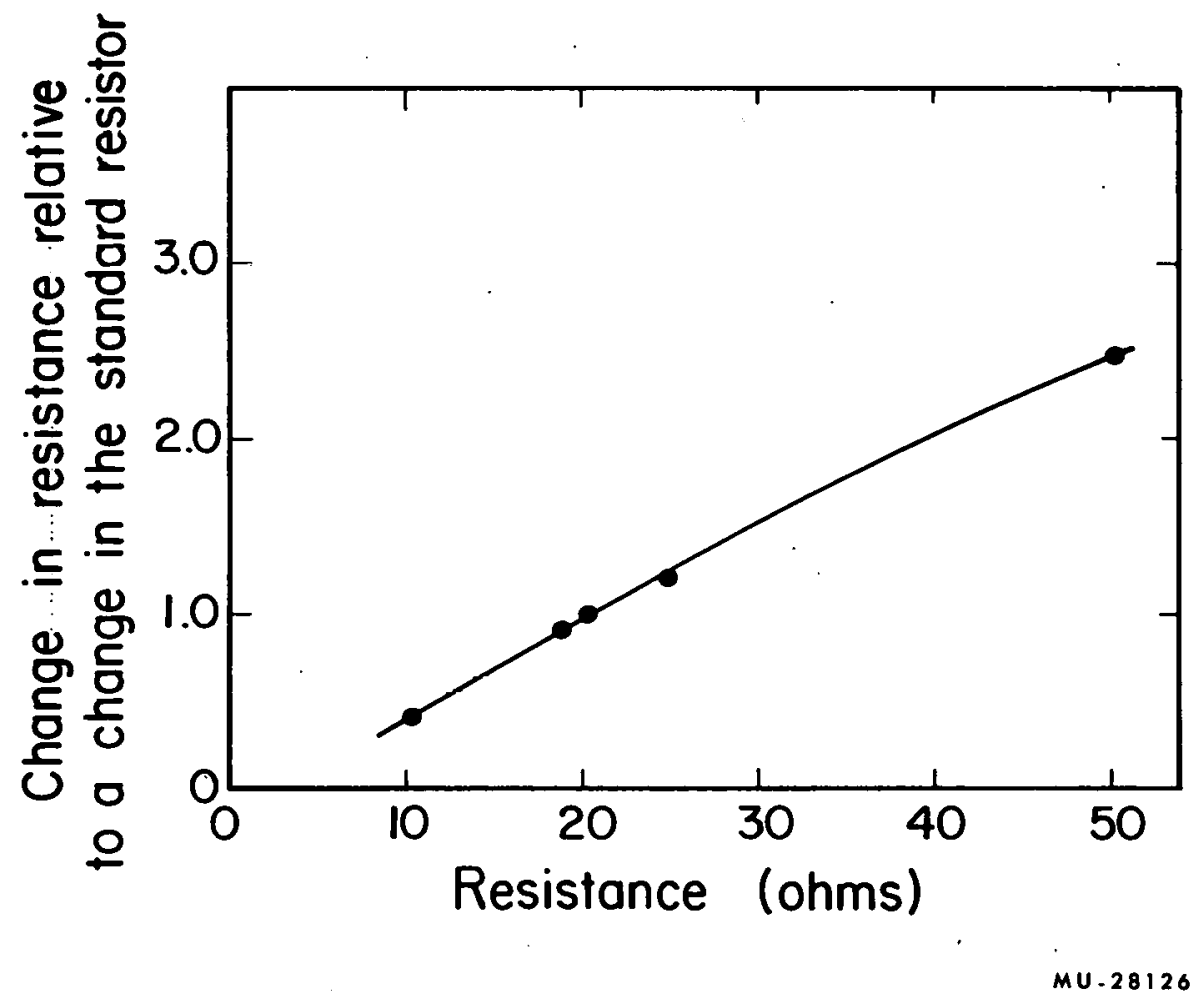

Fig. 11. Response of system to changes in the standard resistor. 


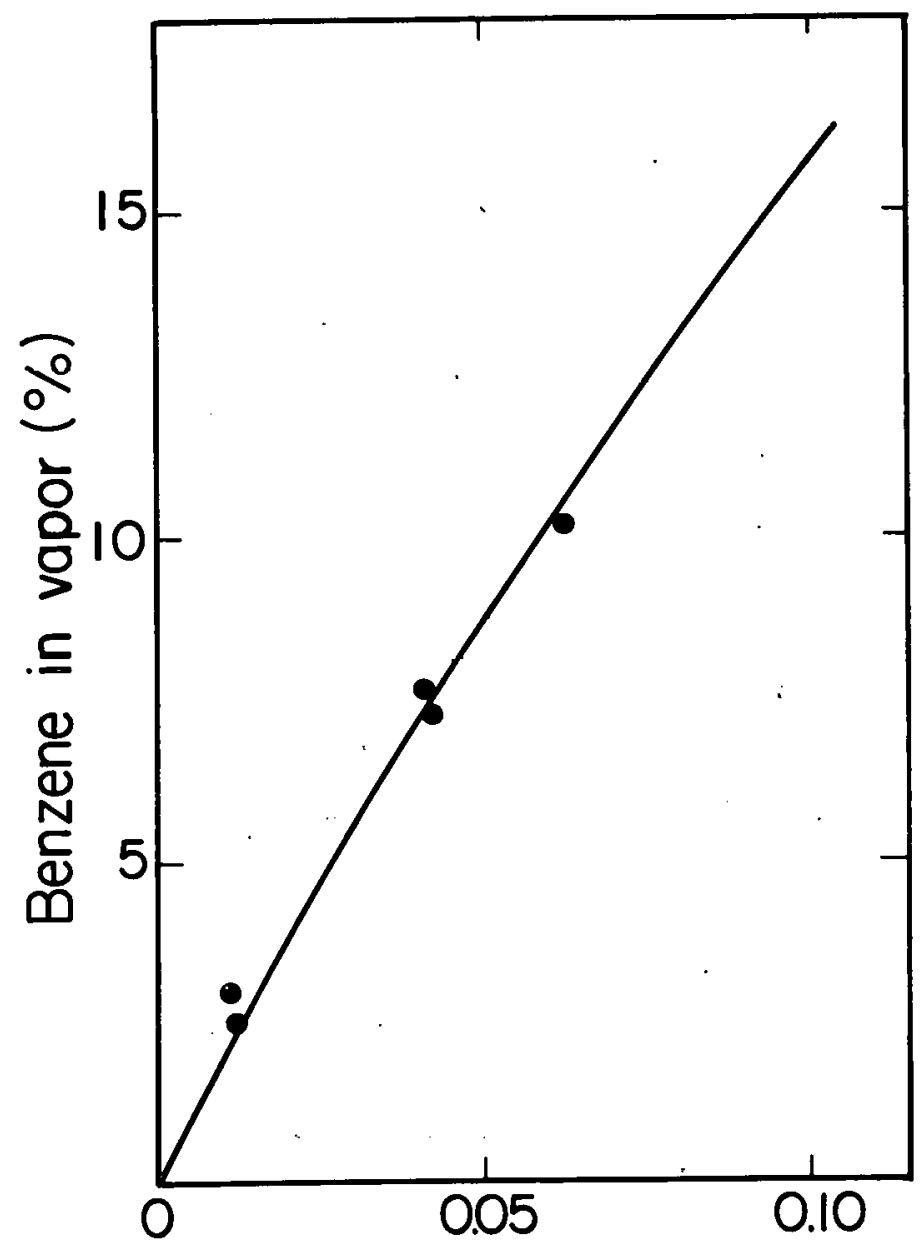

Weight of benzene added(g)

$M U-28127$

Fig. 12. Vapor composition in calibration cell 1. Data points are from mass-spectrometer analysis. The line is the calculated vapor composition. 


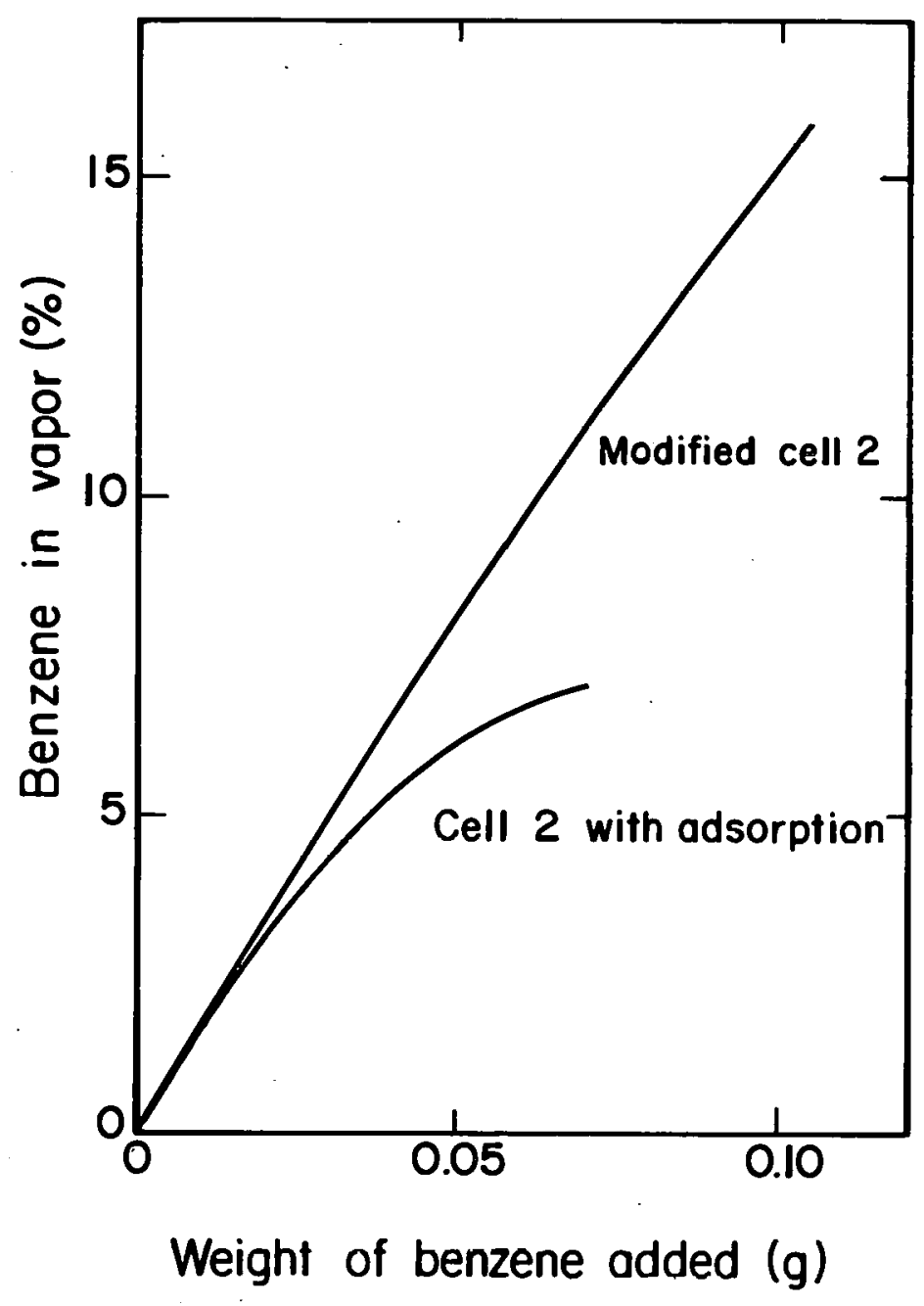

$M U-28128$

Fig. 13. Vapor composition in calibration cell 2. 
microphone cable leads. This cell was accordingly modified to be the same as Cell $l_{9}$. and then both gave the expected gas compositions.

After runs in the Stefan diffusion tube and the calibration cells, the resistance of the probes was measured in air. This was necessary because the resistance of the probes changed slightly with time. The resistance in air gave a base point with which the resistance obtained during the run could be compared. This technique also helped eliminate. contact resistance effects, since the resistance in air was measured with the same connection as had been used during the previous run.

Benzene loss in the Stefan diffusion tube was determined by weighing the tube before and after each run. Weights were determined to the nearest $0.0001 \mathrm{~g}$. While out of the system the tube was kept stoppered at all.times to prevent evaporation of benzene. Liquid depth in the tube was determined from the weight of benzene. Most runs lasted more then 3 hours. A few runs were only 30 to 40 minutes. Although it has been estimated that equilibrium is reached in 15 minutes, these shorter runs gave badly scattered points and were discarded. 


\section{RESULTS AND DISCUSSION}

\section{Theoretical Results}

Velocity and concentration profiles were calculated from Eqs. (7), (25), and (55). First consider the velocity profile. Values of the velocity $u$ were calculated at several values of $x$ and $r_{0}$. The results are shown in Fig。 14。 The velocity profile starts out.flat at $x=0$, and slowly develops into what is essentially a parabolic profile at $x=13$.

Since only the first two eigenvalues were used in these calculations, the values calculated are not yet completely converged, especially at $r=0$ and $r=r_{0}$. At each value of $x$ howeve $r_{2}$. the average velocity $u_{0}$ must be the same, since at steady state the mass flux: is constant throughout the tube. This was taken into account in drawing the velocity profiles. The values $D=0.11 \mathrm{~cm}^{2} / \mathrm{sec}$ and $L=13 \mathrm{~cm}$ are used in the calculations.

Next, concentration profiles were calculated by use of Eqs. (7) and (55). The profile for $C_{0}$ is shown on Fig. 2 (page 7). Since $C_{0}$ is a constant radially it varies only in the $x$ direction.

Values of $C_{1}$ calculated at various values of $x$. and $r$ are given in Table.II. It is immediately. apparent that the contribution of $C_{1}$ to the total concentration profile is insignificant. Thus the concentration profile is given by $C_{0}$ (Fig. 2). The values of $C_{1}$ in Table $\amalg$ are based only on a limited.summation of the series. solution. The values given are only for $m=1$ and for the first four terms in $n$. A check of the magnitude of the terms. for $m=2$ showed that its contribution was approximately $10 \%$ of the first. Thus $\mathrm{C}_{1}$ is given by a rapidly convergent series.

Table.II. Profile of concentration perturbation, $\mathrm{C}_{1}$, given as $\mathrm{C}_{1} / \mathrm{C}_{\mathrm{s}}$.

\begin{tabular}{|c|c|c|c|c|}
\hline \multirow[b]{2}{*}{$\mathbf{x}$} & \multicolumn{4}{|c|}{$r / r_{0}$} \\
\hline & 0 & 0.24 & 0.71 & 0.87 \\
\hline 6 & $=2.7 \times 10^{-5}$ & $-2.2 \times 10^{-5}$ & $0.4 \times 10^{-5}$ & $1.0 \times 10^{-5}$ \\
\hline 13 & 0 & 0 & 0 & 0 \\
\hline
\end{tabular}




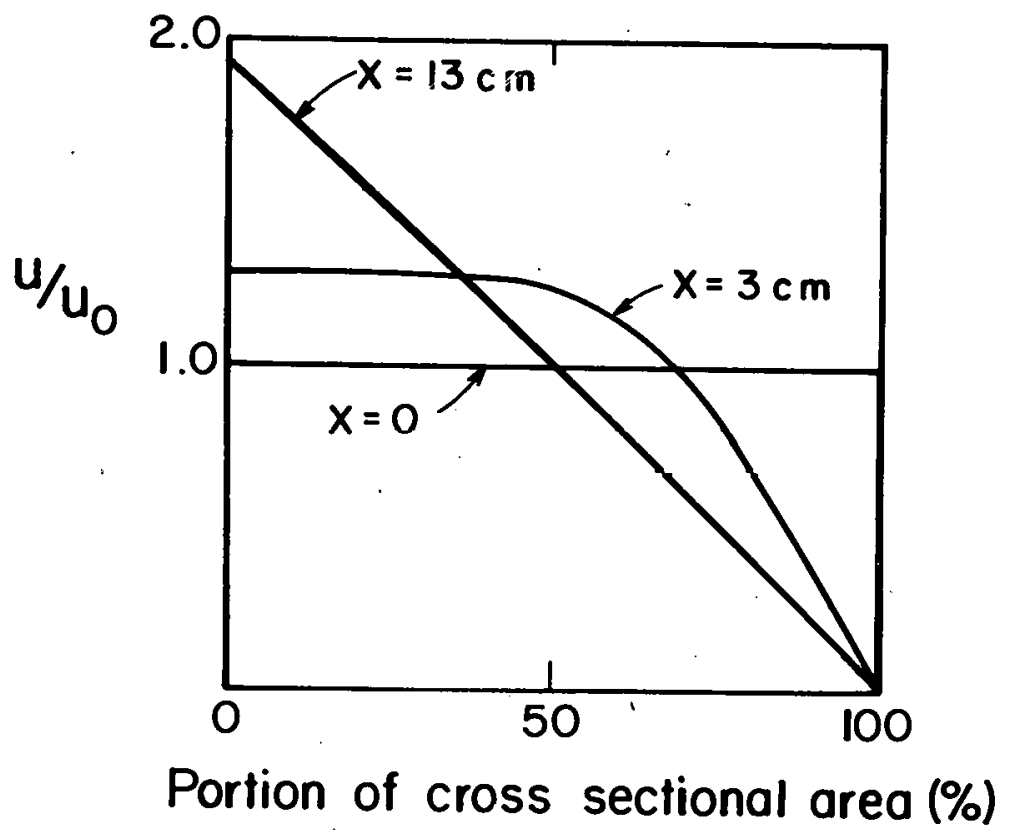

MU.28129

Fig. 14. Velocity profiles in a Stefan diffusion tube. 
Since the concentration profile is essentially that of $\mathrm{C}_{0^{\circ}}$ there is no radial concentration gradient.. Thus the flat concentration profile that was assumed in past interpretation of Stefan-tube data was correct, although there is not a flat velocity profile.

It has been shown that when no radial concentration gradient. exists Eq. (4) can be used to calculate the diffusion coefficient from mass flux data. (See Eqs. 61-64). Thus the assumption of plug velocity and concentration profiles, while not strictly correct, results in a correct equation for the calculation of the diffusion coefficient from the Stefan-tube data.

In developing the velocity and concentration equations it was assumed that the inertia terms and the pressure gradient term in the equations of motion (Eq. 12) could be neglected. To check this assumption, an estimate was made, based on the calculated results, of the relative magnitude of these terms compared with the neglected term. They were found to be much smaller than the viscous.term, as shown on Table III. Thus the assumptions were valid.

- Table. III. - Calculated magnitude of the terms in the convection equation at $\mathbf{x}=3$.

\begin{tabular}{cc}
\hline$\frac{\text { Term }}{\partial \mathrm{x}}$ & $\frac{\text { Magnitude of term }}{1 \times 10^{-9}}$ \\
$u \frac{\partial u}{\partial \mathrm{x}}$ & $6 \times 10^{-6}$ \\
$v \frac{\partial^{2} \mathrm{u}}{\partial \mathrm{x}^{2}}$ & $1 \times 10^{-3}$ \\
\hline
\end{tabular}

The term $\frac{\partial p}{\partial x}$ was evaluated by determining the derivative of the velocity at the wall。

This gave

$$
\left.\frac{\partial u}{\partial r}\right|_{r=r_{0}}=\sum_{k}-\frac{2 u_{0}}{r_{0}} \cos \left(\beta_{k} \frac{x}{r_{0}}\right) .
$$


The :velocity gradient at the wall is related to.the shear stress by

$$
\tau=\mu \frac{d u}{d r} \text {. }
$$

Now if we make a.force balance, we obtain a relationship between $\frac{\partial p}{\partial x}$ and $\frac{\partial u}{\partial r}$

$$
\frac{\mathrm{dp}}{\mathrm{dx}}=-\frac{2}{\mathrm{r}_{0}^{2}} \quad \frac{\mu}{g_{C}} \sum_{k} u_{0} \cos \left(\beta_{k} \frac{x}{r_{0}}\right) .
$$

This expression is then evaluated to give $\frac{d p}{d x}$.

To see the effect of higher mass-transfer rates on the concentration profile, calculations were made. assuming a vapor pressure of $700 \mathrm{~mm} \mathrm{Hg}$. (instead of $148 \mathrm{~mm} \mathrm{Hg}$ vapor pressure of benzene) at.the same total pressure of $748 \mathrm{~mm} \mathrm{Hg}$. This gave a value of $\mathrm{u}_{0}$ that was 15. times the value for benzene. The resultant value of $C_{1}$ was much larger, but still negligible。. Even in this case $C_{1}$ is only $0.1 \%$ of the value of $\mathrm{C}_{0^{\circ}}$. Only in very extreme cases of high vapor pressure and very short diffusion distances will $\dot{C}_{1}$ be appreciable.

\section{Experimental Verification}

Calibration curves for the probes are shown on Figs. 17 through 19. in Appendix B. The probes have a linear response over the entire concentration range studied. The concentration profile measured by the probes is shown on. Fig. 15 and summarized on Table IV. One can see that within the experimental error there is no radial concentration gradient.

The concentration gradient in $\mathbf{x}$ is of interest, since the values for large $x$ (near the top of the tube) fall on the theoretical line but the points nearest the bottom of the tube indicate a considerably higher concentration than expected.

These points were rechecked and consistently gave the same results。 Runs were made:-in which the probe measurements were made in air saturated with benzene by shutting off the system air flow: When the air flow was. started again and the system had reached equilibrium these high values were again obtained. 


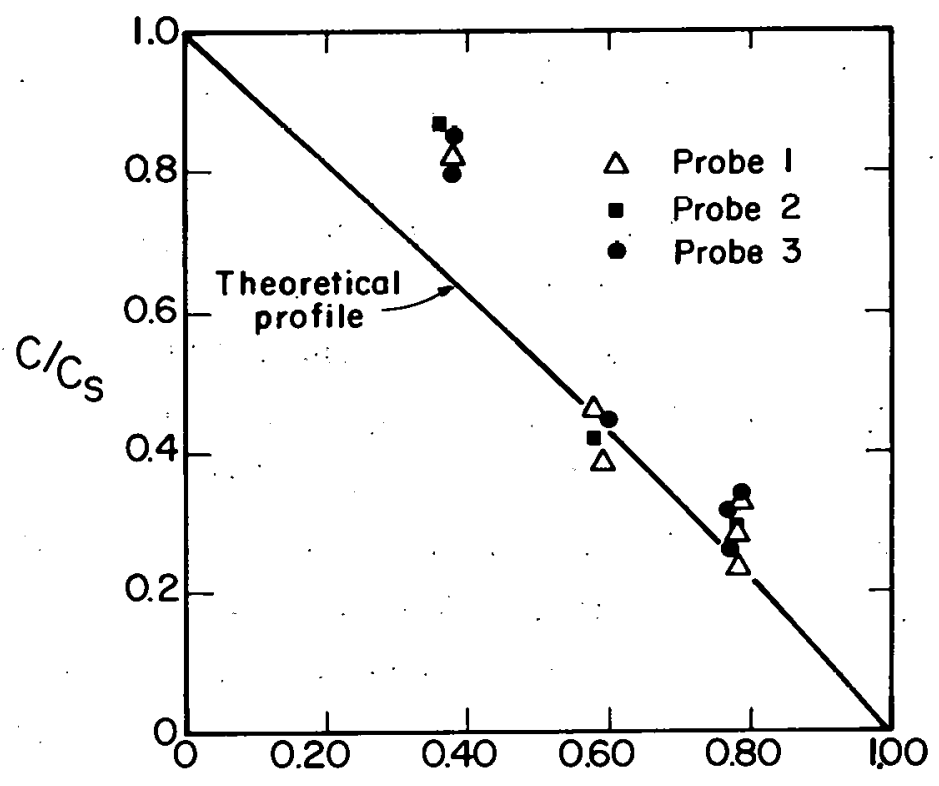

Fraction of diffusion distance

Fig. 15. Experimental concentration profile. 
Table IV. Results obtained in determination of concentration profile.

Probe 1

\begin{tabular}{|c|c|c|c|c|c|}
\hline Run & $.19 \mathrm{M}$ & $2.0 \mathrm{M}$ & $21 \mathrm{M}$ & $22 \mathrm{M}$ & $38 \mathrm{M}$ \\
\hline$\%$ Benzene & 5.6 & 9.1 & 7.8 & 16.5 & 6.5 \\
\hline Probe depth $(\mathrm{cm})$ & 2.84 & 5.36 & 5.36 & 7.88 & 2.84 \\
\hline $\mathbb{C} / \mathrm{C}_{\mathrm{s}}$ & 0.28 & 0.46 & 0.39 & 0.83 & 0.33 \\
\hline $\begin{array}{l}\text { Fraction of diffusion } \\
\text {.. distance }\end{array}$ & 0.78 & 0.58 & 0.59 & 0.39 & 0.78 \\
\hline
\end{tabular}

Probe 2

Run

$\%$ Benzene

$\begin{array}{llc}\frac{15 \mathrm{M}}{8.3} & \frac{16 \mathrm{M}}{5.8} & \frac{17 \mathrm{M}}{17.3} \\ 5.36 & 2.84 & 7.88 \\ 0.42 & 0.29 & 0.87 \\ 0.58 & 0.78 & 0.37\end{array}$

Probe depth, cm

$\mathrm{C} / \mathrm{C}_{\mathrm{s}}$

Fraction of diffusion distance$$
0.58
$$

0.59

0.78

Probe 3

Run

\% Benzene

$25 \mathrm{M}$

$\frac{26 \mathrm{M}}{6.3}$

$\frac{27 \mathrm{M}}{9.0}$

Probe depth, cm

2.84

2.84

5.36

C/C

0.26

0.32

0.45

Fraction of diffusion distance

0.77

0.77

0.59

Probe 3

Run

$\%$ Benzene

$\frac{2.9 \mathrm{M}}{16.1}$

$\frac{3.1 \mathrm{M}}{16.9}$

$\frac{33 \mathrm{M}}{6.6}$

Probe depth, cm

7.88

7.88

2.84

$\mathrm{C} / \mathrm{C}_{\mathrm{s}}$

0.81

0.85

0.33

Fraction of diffusion distance

0.38

0.38

0.78 
Diffusion coefficients were also calculated from the data. The true diffusion coefficient, corrected for end effects, was found according to Eq. (76), to be $0.097 \mathrm{~cm}^{2} / \mathrm{sec}$. This value is somewhat lower than the value of $0.103 \mathrm{~cm}^{2} / \mathrm{sec}$ obtained from the measurements by Lee and Wilke corrected to our conditions. Since some inaccuracies might be expected in our experiment because of interference by the probes, the former measurements are considered preferable. Our data are summarized on Table $V$ in Appendix $C$.

The correction for end effects, $\Delta x$, was found to be $2.04 \mathrm{~cm}$. This is quite large, and offers a possible explanation for the unexpectedly high concentration values near the bottom of the diffusion tube. If this whole end correction is applied to the bottom of the tube, then the predicted concentration profile and the data points are as shown on Fig. 16. The data at the bottom of the table are now much closer to the expected line, but the data at larger values of $x$ now show...some deviation.from the predicted values. However, on the average, this does give a better fit to the data.

A possible cause of the large end effect at the bottom of the tube may be found in the diffusion thermo effect. This effect.is predicted by the kinetic theory of gases, according to which a temperature gradient is set up by a concentration gradient. This effect has been observed experimentally, and temperature differences of several degrees centigrade may be set up. 15

In a binary mixture with a diffusion flow of component 1 there exists a heat flow

$$
\mathrm{J}_{\mathrm{H}}=-a^{\prime} \mathrm{kn} \mathrm{T} \operatorname{grad} \mathrm{N}^{\prime} \text {, }
$$

where $\mathrm{n}$ is the total concentration of molecules 1 and 2 , and $N^{\prime}$ is the mole fraction of molecule 1 , The diffusion thermo-effect coefficient, $a^{\prime}$, for ideal mixtures is related to the thermal diffusion constant, $a$, by 16

$$
a^{\prime}=-D a \text {. }
$$




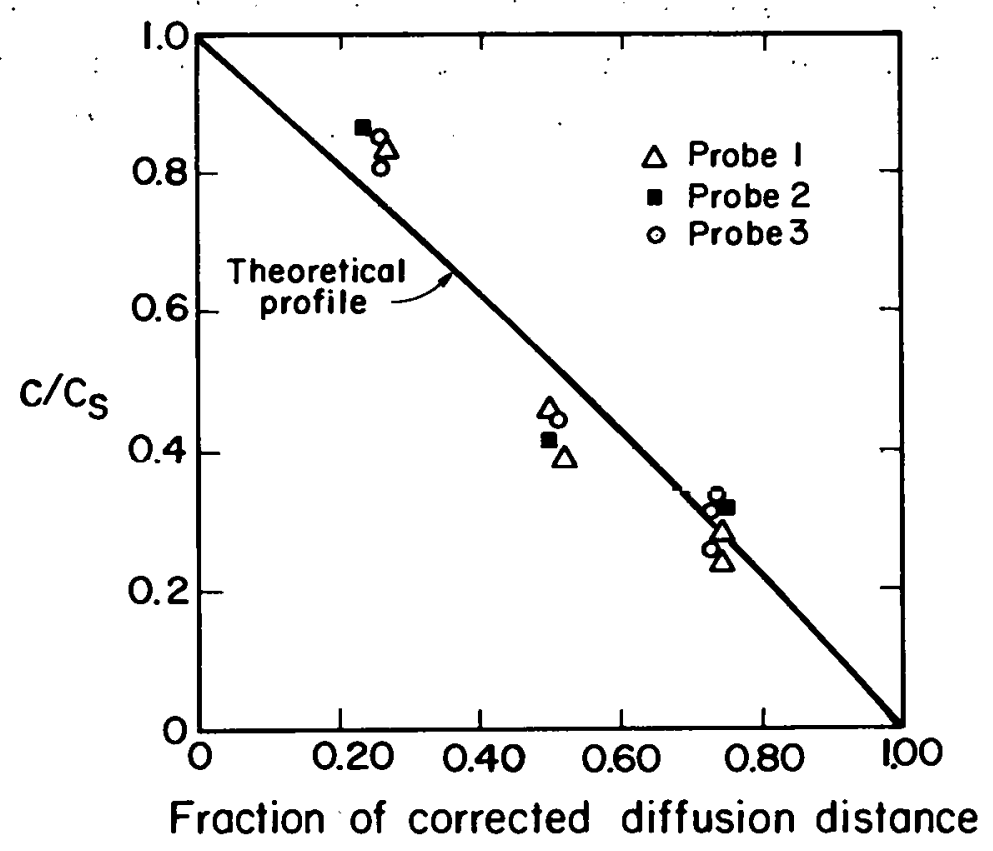

MU -28135

Fig. 16. Experimental concentration profile corrected for end effects. 
Since benzene is the larger and heavier molecule, one would expect a to be positive (i. e., benzene would diffuse toward the cooler end in thermal diffusion). Therefore $a^{\prime}$ would be negative. Thus in Eq. (81), with grad $N^{\prime}$ also negative, the heat flux and the higher temperature would be near the bottom of the tube. Thus one would have a cooler heavier gas on top of a warmer gas layer, starting convection currents. This could cause turbulence at the bottom of the tube and might explain the data points. Further work is required to confirm this. 


\section{CONCLUSIONS}

A theoretical study of the Stefan diffusion-tube system indicates that

(a) the re is no significant radial concentration gradient in the diffusion tube,

(b) the velocity profile, although flat at the liquid surface, becomes parabolic at large distances.

Experiment: studies confirm. that there is no significant concentration gradient within. limitations of the measuring method. From these results it is concluded that equations developed from plug flow models.for the Stefan tube could be used to calculate diffusion coeffi = cients from the data. 


\section{ACKNOWLEDGMENTS}

The help and suggestions of the per sonnel of the Mechanics Shop Building 70, especially Mr. G. G. Young, in construction of the equipment and of Aldo Sciamanina for mass-spectrometer analyses are gratefully acknowledged. 


\section{NOMENCLAT:URE}

$\beta$ root of zero-order Bessel.function of first kind

C . Molar concentration

D diffusion coefficient

$D_{w} \cdot$ diameter of wire

$\nabla \quad$ volumetric coefficient of thermal expansion

$\epsilon$ conversion factor

$h_{c}$ heat-transfer coefficient for free convection

$\mathrm{J}_{0}$ zero-order Bessel function of the first kind

$\mathrm{J}_{1}$. first-order Bessel function of the first kind

$\mathrm{J}_{\mathrm{H}}$ : heat flux

$\mathrm{J}_{\mathbf{T}}$ total mass flow: : $:$.

$\mathbf{k}_{f}$.thermal conductivity of gas film around wire

$\mathrm{le}_{\mathrm{w}}$. thermal conductivity of wrire

$\lambda$ root of the first-order Bessel function of the first kind

N . mass.flux

p partial pressure

P total pressure

$R$ gas constant

$R_{0}$. resistance of wire at $200^{\circ} \mathrm{C}$

$\rho_{f}$ density of gas film around wire

$T$. temperature

$T_{A}$ temperature of gas

$T_{w}$ temperature of wire

$\tau \quad$ shear stress

$\theta$ temperature coefficient of electrical resistance

$u$.velocity in the $x$ direction

$v$ velocity in the $r$ direction

$\checkmark \quad$ kinematic viscosity

$\mu$. absolute viscosity 


\section{APPENDICES}

A. Sample calculation of $C_{1}$ at $x=0$

-...First one must calculate the coefficients $\mathrm{E}_{\mathrm{n}}$. They are obtained from Eq: $(27)$ :

$$
E_{n}=\frac{2 u_{0}}{\beta_{n} J_{1}\left(\beta_{n}\right)}
$$

The value of $u_{0}$ for the benzene-air system is $0,00186 \mathrm{~cm} / \mathrm{sec}$. Values of $\beta_{n}$ and $J_{1}\left(\beta_{n}\right)$ are obtained from Jahnke and Ende, Tables of Functions, 4th ed. (Dover; New York, 1945) p. 166. Then we have the following.

\begin{tabular}{|c|c|c|c|}
\hline $\mathbf{n}$ & $\beta_{n}$ & $\mathrm{~J}_{1}\left(\beta_{\mathrm{n}}\right)$ & $\underset{\mathbf{E}}{\mathbf{n}}$ \\
\hline 1 & 2.405 & 0.5191 & 0.002 .965 \\
\hline 2 & 5.520 & -0.3403 & -0.001978 \\
\hline 3 & 8.654 & 0.27 .15 & 0.001582 \\
\hline 4 & 11.792 & -0.2325 & -0.001359 \\
\hline
\end{tabular}

Now calculate $K, L$, and $M$ for $m=1$. Values used are $\mathrm{D}=0.11 \mathrm{~cm}^{2} / \mathrm{sec}$,

$$
\mathrm{L}=.13 \mathrm{~cm} \text { 。 }
$$

These functions are evaluated from the equations

$$
\begin{aligned}
& \mathbf{K}_{\mathrm{m}}=\mathrm{D} \frac{\mathrm{r}_{0}^{2}}{2} \mathrm{~J}_{0}^{2}\left(\lambda_{\mathrm{m}}\right)^{\prime} \\
& \mathrm{L}_{\mathrm{m}}=\mathrm{u}_{0} \frac{\mathrm{r}_{0}^{2}}{2} \mathrm{~J}_{0}^{2}\left(\lambda_{\mathrm{m}}\right)^{\prime} \\
& \mathbf{M}_{\mathrm{m}}=\mathrm{D} \frac{\lambda_{\mathrm{m}}^{2}}{2} \mathrm{~J}_{0}^{2}\left(\lambda_{\mathrm{m}}\right)
\end{aligned}
$$


Then

$$
\begin{aligned}
\mathrm{K}_{1} & =0.01439 \\
\mathrm{~L}_{1} & =0.000244 \\
\mathrm{M}_{1} & =0.131
\end{aligned}
$$

Now calculate $\phi$ and $\gamma$ from

$$
\begin{aligned}
& \phi=K A^{2}-K B_{n}^{2}-L A-M \\
& y=L B_{n}-2 K A B_{n}
\end{aligned}
$$

where

$$
A=\frac{\mathbf{u}_{0}}{\mathrm{D}} ; \quad \mathbf{B}_{\mathrm{n}}=\frac{\boldsymbol{\beta}_{\mathbf{n}}}{\mathbf{r}_{0}}
$$

Then

$$
\begin{aligned}
& . \phi_{11}=(0.0143 .9)(0.000286)-(0.0143 .9)(1.89)^{2}-(0.000244)(0.016 .9)-0.131 \\
& =-0.183 \text {, } \\
& \ddot{\phi}_{12}=-0.403 \text {, } \\
& \phi_{13}=-0.799 \\
& \phi_{14}=-1.463 \\
& x_{11}=1.89(0.000244-2(0.01439)(0.0169))=-0.000457 \\
& \gamma_{12}=-0.001051 \\
& \gamma_{13}=-0.0 .0165 \text {, } \\
& \ddot{x_{14}}=-0.002243 .
\end{aligned}
$$


Now $g_{n}$ is calculated from the equation

$g_{n}=E_{n} \frac{C_{S} u_{0}}{D}\left(\frac{\exp \left(-u_{0} L / D\right)}{1-\exp \left(-u_{0} L / D\right)}\right)\left(\frac{r_{0}{ }^{2} \beta_{n}}{\beta_{n}^{2}-\lambda_{m}^{2}}\right) J_{1}\left(\beta_{n}\right) J_{0}\left(\lambda_{m}\right)$

The value of $\lambda_{1}$ is 3.8317 , and

$$
J_{0}\left(\lambda_{1}\right)=-0.4028
$$

Now

$$
\frac{C_{s_{0}}^{u_{0}}}{D}\left(\frac{\exp \left(-u_{0} L / D\right)}{1-\exp \left(-u_{0} L / D\right.}\right) r_{0}{ }^{2} \cdot J_{0}\left(\lambda_{1}\right)=-0.0446 C_{s}
$$

\begin{tabular}{|c|c|c|c|c|}
\hline $\mathbf{n}$ & $\mathbf{E}_{\mathbf{n}}$ & $\beta_{n}$ & $J_{1}\left(\beta_{n}\right)$ & $g_{n}$ \\
\hline 1 & 0.002965 & 2.405 & 0.5191 & $0.0000204 C_{S}$ \\
\hline 2 & -0.001978 & 5.520 & -0.3403 & $-0.00001 .16 C_{S}$ \\
\hline 3 & 0.001582 & 8.654 & 0.2715 & $-0.0000030 \mathrm{C}_{\mathbf{S}}$ \\
\hline 4 & -0.001359 & 11.7 .92 & -0.2325 & $-0.0000015 C_{s}$ \\
\hline
\end{tabular}

Then we have the values shown in the table.

Now

$$
H_{m, n}=-g_{n} \frac{\gamma_{m, n}}{\phi_{m, n}^{2}+\gamma_{m, n}^{2}}
$$

$H_{11}=0.0000204 C_{S}\left(\frac{0.000457}{(-0.183)^{2}+(0.000457)^{2}}\right)=2.78 \times 10^{-7} C_{S}$ 
Likewise

$$
\begin{aligned}
& \mathrm{H}_{12}=-7.51 \times 10^{-8} \text {, } \\
& H_{13}=-7.73 \times 10^{-9} \text {, } \\
& \mathrm{H}_{14}=-1.57 \times 10^{-9} \text {; } \\
& G_{11}=-g_{n} \frac{\phi_{11}}{\phi_{11}^{2}+\gamma_{11}^{2}} \\
& =-0.0000204 C_{S}\left(\frac{0.183}{(0.183)^{2}+(0.000457)^{2}}\right) \simeq \frac{-0.0000204 C_{S}}{0.183}=-0.0001115 C_{S}
\end{aligned}
$$

Also

$$
\begin{aligned}
& \mathrm{G}_{12}=0.0000288 \mathrm{C}_{S^{\prime}} \\
& \mathrm{G}_{13}=0.00000375 \mathrm{C}_{\mathbf{S}^{\prime}} \\
& \mathrm{G}_{14}=0.0000 .0102 \mathrm{C}_{\mathbf{S}^{\circ}}
\end{aligned}
$$

Now apply boundary. conditions to get $S, T$ :

$$
\mathbf{S}_{\mathrm{m}}+\mathrm{T}_{\mathrm{m}}=-\sum_{\mathbf{n}} \mathrm{G}_{\mathrm{m}, \mathbf{n}}
$$

or

$$
S_{1}+T_{1}=0.0000779 C_{S}
$$


At $\mathrm{X}=\mathrm{L}$

$$
\begin{aligned}
& S_{1} \exp \left(m_{1} L\right)+T_{1} \exp \left(m_{2} L\right)+ \\
& \exp (A L) \sum_{n}\left(G_{1, n} \cos B_{n} L+H_{1, n} \sin B_{n} L\right)=0
\end{aligned}
$$

One can immediately see that $H_{1, n}$ is negligible compared with $G_{1, n^{\circ}}$

\begin{tabular}{|c|c|c|c|}
\hline$\underline{\mathbf{n}}$ & $\mathrm{B}_{\mathrm{n}} \mathrm{L}$ & $\cos B_{n} I$ & $G_{1, n} \cos B_{n} L$ \\
\hline 1 & 24.57 & 0.846 & $-0.0000944 C_{S}$ \\
\hline 2 & 56.55 & 1.00 & $0.0000288 \mathrm{C}_{S}$ \\
\hline 3 & 88.53 & 0.844 & $0.0000032 \mathrm{C}_{S}$ \\
\hline 4 & 120.51 & -0.427 & $-0.0000004 C_{S}$ \\
\hline
\end{tabular}
Therefore we have the values in the table

Only the first four terms are used, since the series converges rapidly. Now

$$
\begin{aligned}
& b_{1}=\frac{L+\sqrt{L^{2}+4 K M}}{2 K}=3.03 \\
& b_{2}=\frac{L-\sqrt{L^{2}+4 K M}}{2 K}=-3.02
\end{aligned}
$$

Therefore

$$
\begin{gathered}
S_{1} e^{39.39}+T_{1} e^{-39.36}+0.0000782 C_{S}=0 \\
S_{1} \simeq 0 ; \quad \therefore \because ;
\end{gathered}
$$

Therefore

$$
\mathbf{T}_{1} \simeq 0.00007 .79 \mathrm{C}_{\mathbf{s}}
$$


Since $S_{1}$ is negligible, we can get $C_{1}$ for $m=1$ from

$$
C_{1}=T_{1} \exp \left(m_{2} x\right)+\exp (A x) \sum_{n} \cdot G_{1, n} \cos B_{n} x \text {. }
$$

With $x=6 \quad T$ is also negligible and one gets $C_{1}=-0.0000271 C_{S^{\circ}}$ A calculation for $m=2$ shows a correction of about $0.000003 C_{S}$ to the value of $\mathrm{C}_{1}$, indicating rapid convergence of the series. 
i

B. Probe calibration curves 


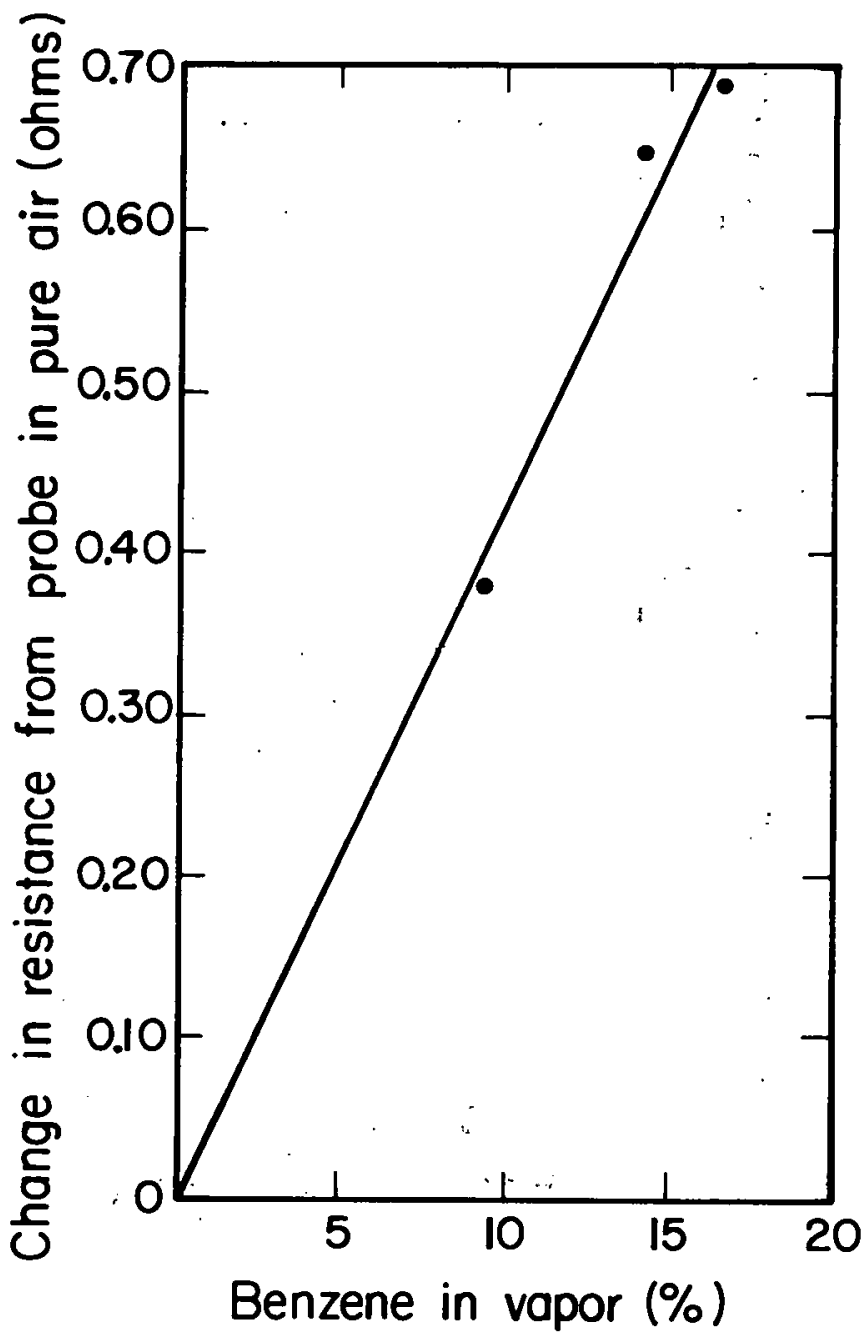

$M U .28131$

Fig. 17. Calibration curve for probe 1. 
$\because-62-$

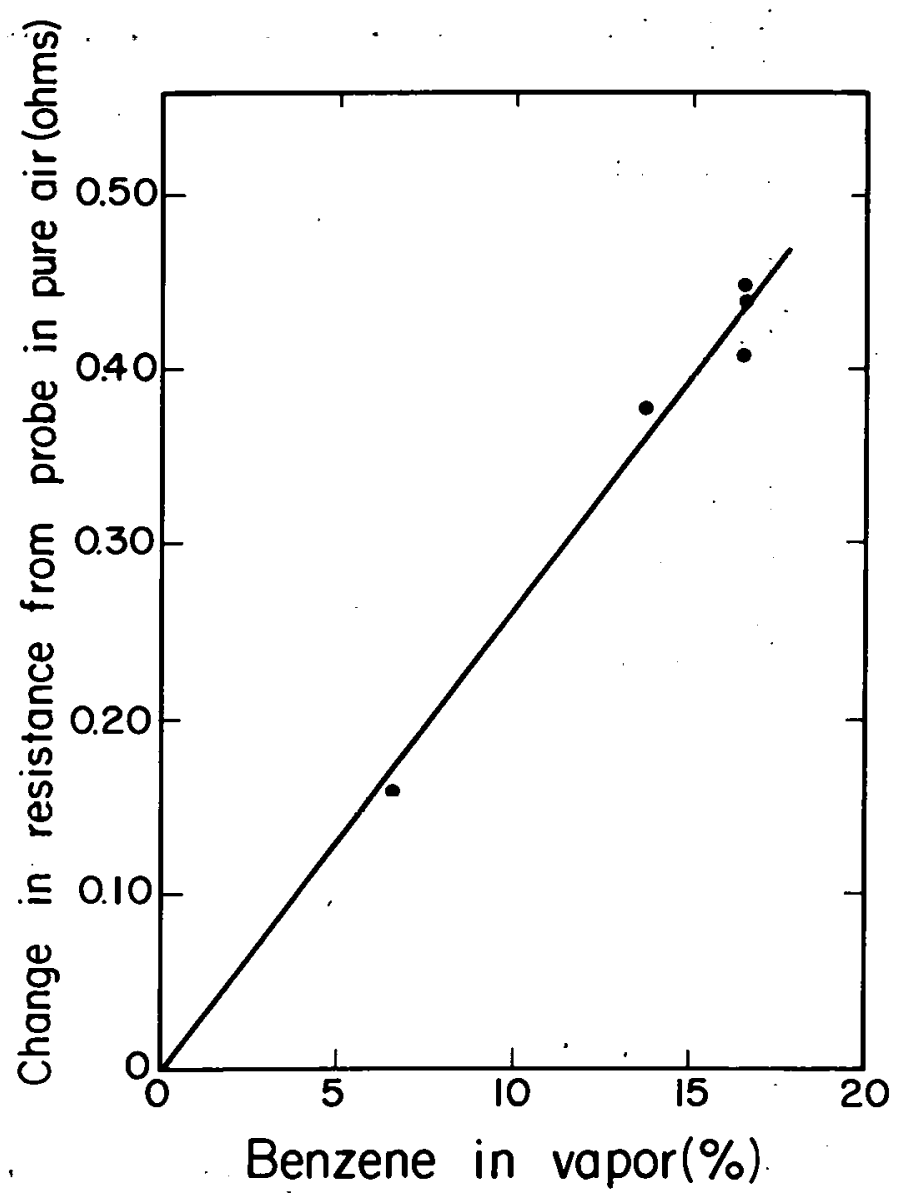

MU. 28132

Fig. 18. Calibration curve for probe 2. 


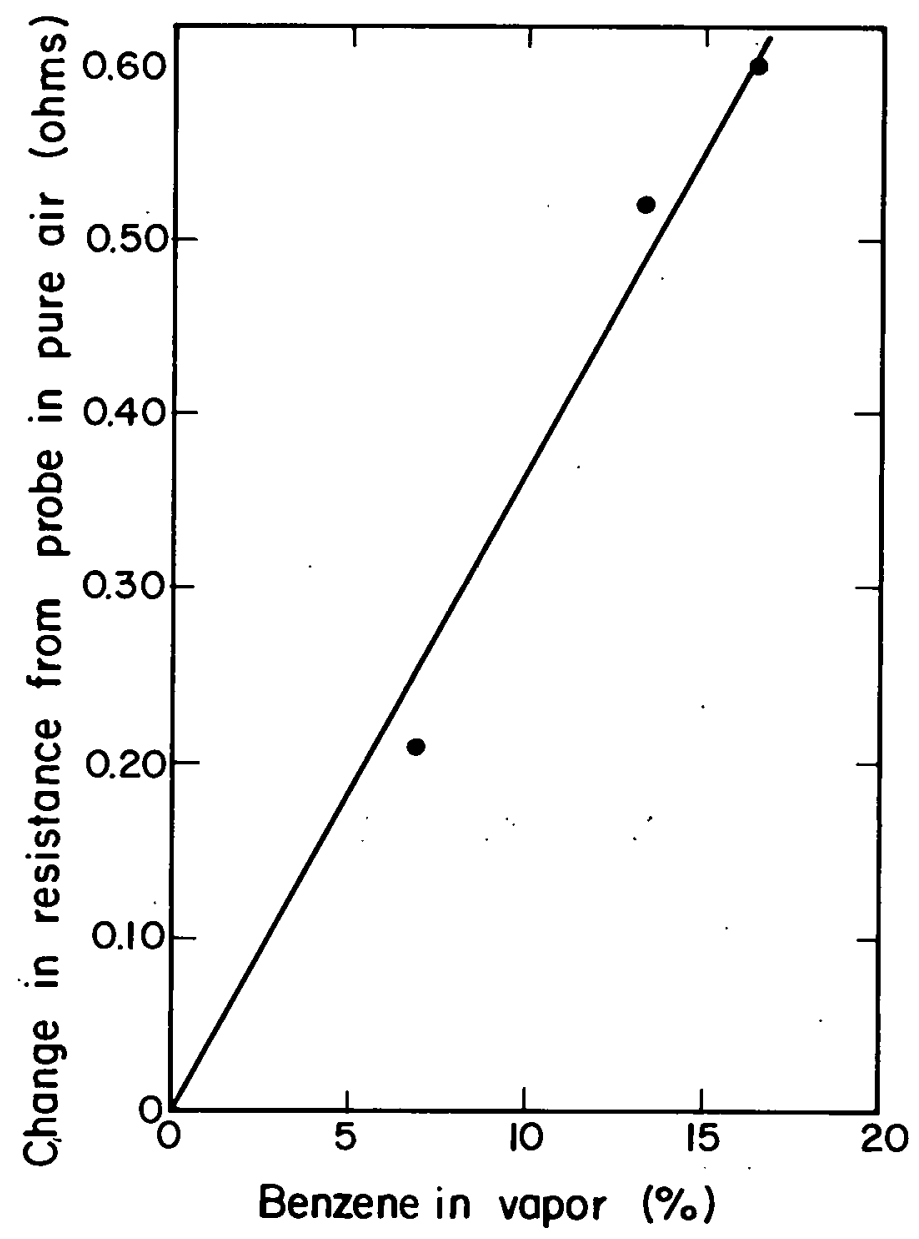

$M U .28133$

Fig. 19. Calibration curve for probe 3. 
$-64-$

C. Diffusion Data Summary 
Table $V_{0}$. Diffusion data. Benzene-air at $35^{\circ} \mathrm{C}$.

\begin{tabular}{|c|c|c|c|c|c|c|}
\hline $\begin{array}{l}\text { Run } \\
\text { number }\end{array}$ & $\begin{array}{c}\text { Weight } \\
\text { loss } \\
\text { (g) } \\
\end{array}$ & $\begin{array}{l}\text { Time } \\
\text { or run } \\
\text { (min) } \\
\end{array}$ & $\begin{array}{l}\text { Diffusion } \\
\text { distance }\end{array}$ & $\begin{array}{c}\text { Pressure } \\
(\mathrm{mm} \\
\mathrm{Hg}) \\
\end{array}$ & Probe & $\begin{array}{r}\text { Depth } \\
(\mathrm{cm}) \\
\end{array}$ \\
\hline $\mathbb{I M}$ & 0.8851 & 592.0 & 15.13 & 746.8 & none & \\
\hline $2 \mathrm{M}$ & 0.6726 & 254.0 & 9.60 & .746 .1 & none & \\
\hline$: 3 \mathrm{M}$ & 0.8476 & 350.0 & 9.77 & 745.6 & none & \\
\hline $4 \mathrm{M}$ & d. 2490 & .7 .25 .0 & 12.98 & .743 .6 & none & \\
\hline $.5 \mathrm{M}$ & 1.0307 & 500.0 & 11.18 & .745 .6 & none & \\
\hline $6 \mathrm{M}$ & 1.1228 & .710 .0 & 14.17 & .744 .4 & none & \\
\hline $8 \mathrm{M}$ & 0.5699 & 298.0 & 12.90 & .748 .0 & 1 & .. 2.84 \\
\hline $9 \mathrm{M}$ & 2.3237 & 325.0 & 12.75 & .747 .9 & 1 & 2.84 \\
\hline $10 \mathrm{M}$ & 1.0.196 & 585.2 & 13.07 & .748 .5 & 1 & 2.84 \\
\hline $11 \mathrm{M}$ & 1.4908 & 813.8 & 12.72 & .748 .5 & none & \\
\hline $12 \mathrm{M}$ & 0.6082 & 330.0 & 12.79 & 746.9 & none & \\
\hline $13 \mathrm{M}$ & 0.6623 & 345.0 & 12.53 & .746 .5 & 3 & 2.84 \\
\hline $1.5 \mathrm{M}$ & 0.6380 & 350.0 & .12 .72 & .746 .8 & 2 & 5.36 \\
\hline $16 \mathrm{M}$ & 1.4214 & 823.0 & 12.94 & 7.46 .7 & 2 & 2.84 \\
\hline $1.7 \mathrm{M}$ & 0.5668 & 305.0 & $: 12.40$ & 746.6 & 2 & 7.88 \\
\hline $18 \mathrm{M}$ & 0.8833 & 306.2 & 9.43 & 746.6 & 2 & 7.88 \\
\hline $1.9 \mathrm{M}$ & 0.4369 & 240.0 & 12.70 & .748 .1 & 1 & 2.84 \\
\hline $20 \mathrm{M}$ & 0.32 .79 & 180.0 & 12.79 & .748 .9 & 1 & 5.36 \\
\hline $21 \mathrm{M}$ & 1.3389 & 796.5 & 13.02 & .749 .0 & 1 & 5.36 \\
\hline $22 \mathrm{M}$ & 0.59 .90 & 336.0 & 12.75 & .748 .1 & 1 & 7.88 \\
\hline $24 \mathrm{M}$ & 0.2808 & .117 .0 & 9.85 & 747.0 & 1 & 7.88 \\
\hline $25 \mathrm{M}$ & 0.4715 & 252.0 & 12.44 & 746.8 & 3 & 2.84 \\
\hline $26 \mathrm{M}$ & 0.2647 & 140.0 & .12 .52 & 747.0 & 3 & 2.84 \\
\hline $27 \mathrm{M}$ & 0.97 .63 & .552 & .12 .74 & .747 .3 & 3 & 5.36 \\
\hline $28 \mathrm{M}$ & 0.2720 & 160.0 & 12.86 & 748.4 & 3 & 5.36 \\
\hline $29 \mathrm{M}$ & 0.4001 & 215.0 & 12.70 & .747 .8 & 3 & 7.88 \\
\hline $30 \mathrm{M}$ & 0.6538 & 255.0 & 9.96 & .749 .2 & 3 & 7.88 \\
\hline $31 \mathrm{M}$ & 0.2026 & 105.0 & 12.59 & .748 .4 & 3 & 7.88 \\
\hline
\end{tabular}




\section{REFERENCES}

1. J. C. Maxwell, Scientific Papers, Vol. 2 (Dover, New York, 1952).

2. J. Stefan, Sitzber。Akad, Wiss: Wien, Math.-naturw。 K1: 63, Abt II (1871).

3. Ibid.65, Abt II '323 (1872)。

4. C. R。 Wilke, Chem。Eng。 Progr。46, 95 (1.950).

5. R. B. Bird, W. E. Stewart, and E. N. Lightfoot, Transport Phenomena (John Wiley and Sons, Inc. New York, 1960), p. 502.

6. Ibid. p. 85 .

7. Ibid. p. 559 .

8. H. Schlichting, Boundary Layer Theory (McGraw-Hill Book Company, Inc。, New York, 1955), p。 83.

9. Ho S. Carslaw and J. Co Jaeger, Conduction of Heat in Solids, 2nd Ed: (Oxford University. Press, London, 1.959), p. 196.

10. H. S. Mickley, T. K. Sherwood, and C. E. Reed, Applied Mathematics in Chemical Engineering, 2nd Ed. (McGraw-Hill Book Company. Inc。, New York, 1957), po 153.

11. R. B. Bird, W. E. Stewart, and E. N. Lightfoot, op。cit。, p. 131.

12. C. Y。 Lee and C. R。 Wilke, Ind: Eng. Chem。 46, 2381 (1954).

13. Richard W. Getzinger, Steady-State Diffusion in Ternary Gas Mixtures (M. S. Thesis), University of California, 1.962 。

14. Chemical Engineers Handbook, edited by Perry, 3rd Ed. (McGraw-Hill Book Company, Inc., New York, 1950).

15. W. Jost, Diffusion in Solids, Liquids, and Gases, 3rd Printing (Academic Press, Inc., New York. 1960), p. 520。

16. R. Hasse, Z。 Physik 127, 1 (1950)。 
This report was prepared as an account of Government sponsored work. Neither the United States, nor the Commission, nor any person acting on behalf of the Commission:

A. Makes any warranty or representation, expressed or implied, with respect to the accuracy, completeness, or usefulness of the information contained in this report, or that the use of any information, apparatus, method, or process disclosed in this report may not infringe privately owned rights; or

B. Assumes any liabilities with respect to the use of, or for damages resulting from the use of any information, apparatus, method, or process disclosed in this report.

As used in the above, "person acting on behalf of the Commission" includes any employee or contractor of the Commission, or employee of such contractor, to the extent that such employee or contractor of the Commission, or employee of such contractor prepares, disseminates, or provides access to, any information pursuant to his employment or contract with the Commission, or his employment with such contractor. 